\title{
The Response of Orographic Precipitation over Idealized Midlatitude Mountains Due to Global Increases in $\mathrm{CO}_{2}$
}

\author{
XiaOming Shi And Dale R. DurRan \\ Department of Atmospheric Sciences, University of Washington, Seattle, Washington
}

(Manuscript received 1 August 2013, in final form 7 December 2013)

\begin{abstract}
The sensitivity of stratiform midlatitude orographic precipitation to global mean temperature is investigated through numerical simulations. As a step toward understanding the relative influence of thermodynamic and dynamical processes on orographic precipitation, simple idealizations of Earth's major north-south mountain chains are considered. The individual terrain elements occupy four islands equally spaced around the Northern Hemisphere of a planet otherwise covered by ocean. Although these mountains have very little influence on the sensitivity of the zonally averaged precipitation to changes in global mean surface temperature, the precipitation on the windward slopes of the ridges is highly sensitive to such changes. When the ridges run between $40^{\circ}$ and $60^{\circ} \mathrm{N}$, the windward-slope hydrological sensitivity exceeds the ClausiusClapeyron scaling of about $7 \% \mathrm{~K}^{-1}$ over the northern half of the barrier, leading to substantial precipitation changes. The annual accumulated orographic precipitation is modified by changes in both the mean precipitation intensity and the changes in the number of hours during which precipitation occurs. The changes in the number of hours with significant precipitation largely results from modifications in synoptic-scale storminess associated with changes in the midlatitude storm tracks. A simple diagnostic model reveals the primary factors modifying the mean orographic precipitation intensity are variations in 1) the moist adiabatic lapse rate of saturation specific humidity, 2) the wind speed perpendicular to the mountain, and 3) the vertical displacement of saturated air parcels above the windward slope. The strong dependence of 2 and 3 on latitude further confirms that changes in midlatitude storminess are a major factor determining the response of orographic precipitation to global warming.
\end{abstract}

\section{Introduction}

Orographic precipitation replenishes a large fraction of the world's freshwater supply. About $26 \%$ of the world's population lives within mountains or their foothills, and over $40 \%$ live in river basins originating in mountainous regions (Beniston 2005). Heavy orographic precipitation on the other hand, can have less benign impacts, including triggering landslides and flash floods that produce significant loss of life and substantial disruption of the local economy (Maddox et al. 1978; Lin et al. 2001; Rasmussen and Houze 2012). Assessing how orographic precipitation may be altered in response to global warming is therefore an urgent problem.

Considerable progress has been made in understanding the change in global mean precipitation that will occur as

Corresponding author address: Xiaoming Shi, Box 351640, Dept. of Atmospheric Sciences, University of Washington, Seattle, WA 98195.

E-mail: shixm@atmos.washington.edu the climate warms. Global climate models suggest that the relative humidity will remain roughly constant, implying through the Clausius-Clapeyron (CC) equation an increase in atmospheric water vapor of about $7 \% \mathrm{~K}^{-1}$ of surface warming. The strength of the hydrological cycle is constrained, however, not simply by the water vapor content of the air, but also by the need to balance the latent heating accompanying increased precipitation with additional longwave radiative cooling (Allen and Ingram 2002; Takahashi 2009; O'Gorman et al. 2012). Global climate models suggest that this energetic constraint will limit increases in global mean precipitation to roughly $2 \% \mathrm{~K}^{-1}$ of surface warming (Held and Soden 2006; Liepert and Previdi 2009).

Constraints on the global energy budget do not apply to local regions, such as Earth's mountains. In this study we conduct simulations with a general circulation model to assess the local changes in midlatitude orographic precipitation that might occur over idealized northsouth mountain barriers. An elementary idealization of stable upslope orographic precipitation, which has seen 
some real-world application (Alpert 1986), assumes that the air at all levels is saturated and flowing parallel to the underlying topography with slope $\alpha$ and approximates the precipitation rate per unit area $P$ as

$$
P=\alpha U q_{s}(0) \rho(0)
$$

here $q_{s}$ is the saturation specific humidity and $\rho$ is the density of the moist air, both of which are evaluated at the surface $(z=0)$, and $U$ is the vertically averaged speed of the slope-perpendicular flow (Smith 1979, p. 175). If $U$ does not change in response to global warming, (1) suggests that stable upslope orographic precipitation would increase in response to surface warming at the CC rate.

Relatively few previous studies have focused on how global warming may influence the processes regulating stable orographic precipitation, such as that commonly generated by westerly flow across north-south mountain ranges such as the Rockies and the Andes. Moving beyond (1), Kirshbaum and Smith (2008) examined the influence of upstream temperature and moist stability on idealized simulations of precipitating cross-mountain flows representative of those impinging on midlatitude mountains. They found that the precipitation increased at rates well below the $\mathrm{CC}$ scaling in response to surface temperature increases when other environmental parameters (winds, static dry stability, and relative humidity) were held constant. They determined the most important factor producing the sub-CC scaling was the relatively slow rate at which the vertically averaged condensation increases in response to surface temperature increases. This finding is consistent with other studies showing that the sensitivity of $d q_{s} / d z$ to surface temperature provides a better scaling for precipitation and condensation occurring in a cloud layer of roughly constant depth than does the increase in total column water vapor in a warmer climate (Betts and Harshvardhan 1987; O'Gorman and Schneider 2009). A second important factor identified by Kirshbaum and Smith (2008) was that as the temperature increased, ice-phase precipitation growth was replaced by less efficient warmrain processes. In an idealized study representative of the northern Alps, Zängl (2008) also found the temperature dependence of orographic precipitation was strongly influenced by changes in precipitation microphysics, particularly those associated with variations in the freezing level.

Both Kirshbaum and Smith (2008) and Zängl (2008) conducted process studies focused on the response of orographic precipitation to changes in temperature without considering the influence of circulation shifts that might lead to stronger or weaker cross-mountain winds and water vapor fluxes in a warmer climate-that is, without investigating changes in $U$, the other factor in the simple estimate (1). Most global climate models do, however, predict significant changes in the circulation in response to global warming, such as poleward shifts in the storm tracks (e.g., Yin 2005). To partially account for changes in the global mean climate, shifts in the mean atmospheric state have been incorporated in "pseudoglobal warming" investigations of snow depth over the mountains of Japan (Hara et al. 2008) and Colorado (Rasmussen et al. 2011). Nevertheless, even pseudoglobal warming simulations cannot account for changes in storminess, since they are based on regional model simulations driven at their upstream boundaries by weather perturbations whose strength and frequency match those in the current climate.

The goal of this study is to compare the roles played by thermodynamics and dynamics in regulating midlatitude orographic precipitation in a warmer climate. In particular we will examine the impacts of temperature and humidity changes, shifts in the mean circulation, and changes in the frequency of midlatitude cyclones. To isolate the most relevant variables and side-step uncertainties about the precise future changes in the midlatitude jets and storm tracks Ulbrich et al. (2008), we greatly simplify Earth's actual topography and conduct general circulation model (GCM) simulations of an ocean-covered Earth pierced by simple idealized representations of major north-south midlatitude mountains.

In section 2 we describe the design of our numerical experiments. Section 3 presents the model climatology, with a focus on midlatitude orographic precipitation and its changes in response to doubling of the $\mathrm{CO}_{2}$ concentration. Important factors driving changes in local orographic precipitation are analyzed in sections 4 and 5 using a simple diagnostic model to better understand the stable (grid resolved) orographic precipitation predicted by the GCM. Section 6 contains the conclusions.

\section{Experimental design}

The GCM used in this study is the global atmosphere model developed by the Geophysical Fluid Dynamics Laboratory (GFDL) (Anderson et al. 2004). Standard physics packages and parameters of the GFDL Atmospheric Model, version 2.1 (AM2.1), are adopted in our simulations unless otherwise specified in the following text. Thus our description of the AM2.1 components is very brief. Readers interested in the details of the AM2.1 physics schemes or dynamics are referred to Anderson et al. (2004) and references therein.

AM2.1 has a finite-volume dynamical core on a latitudelongitude grid (Lin 2004), which in our simulations has 
a resolution of $0.5^{\circ}$ latitude by $0.625^{\circ}$ longitude $(\sim 50 \mathrm{~km})$, with 24 vertical levels. Most of the planet is covered by a slab ocean except there are four islands symmetrically distributed at $90^{\circ}$ intervals around the northern midlatitudes. Those islands extend $5^{\circ}$ east-west in longitude and span either the latitude band $35^{\circ}-55^{\circ} \mathrm{N}$ or $40^{\circ}-60^{\circ} \mathrm{N}$. A smooth ridge runs the length of each island; its elevation $z_{s}$ is determined by

$$
z_{s}(x, y)=\frac{h_{0}}{2} \begin{cases}1+\cos (\pi r), & \text { if }|r|<1, \\ 0, & \text { otherwise }\end{cases}
$$

where $r(x, y)$ is defined as

$$
r(x, y)= \begin{cases}\sqrt{\left(\frac{x-x_{0}}{2.5}\right)^{2},} & \text { if }|y-50| \leq 8, \\ \sqrt{\left(\frac{x-x_{0}}{2.5}\right)^{2}+\left(\frac{\left|y-y_{0}\right|-8}{2}\right)^{2}}, & \text { otherwise. }\end{cases}
$$

Here $x$ and $y$ are longitude and latitude in degrees, $\left(x_{0}\right.$, $\left.y_{0}\right)$ is the longitude and latitude of the center of the island, and the ridge height is $h_{0}=2 \mathrm{~km}$. Figure 1 shows the geometry of a single mountain defined by $z_{s}(x, y)$. The resulting mountain is about $2000 \mathrm{~km}$ long and $350 \mathrm{~km}$ wide and as such represents an idealized segment of major north-south mountain ranges such as the Rockies (4800 km long) or the Andes (7000 km long).

As detailed in Anderson et al. (2004), grid-resolved clouds and precipitation in AM2.1 are parameterized with the aid of prognostic variables for the cloud fraction and the specific humidities of cloud liquid water and cloud ice. Grid-scale fluxes of rain and snow are computed diagnostically from these prognostic fields using parameterizations that attempt to account for the subgrid-scale moisture distribution, the determination of liquid water fraction in mixed-phase clouds, and the dependence of the autoconversion threshold on subgridscale nonuniformities in the cloud distribution (Rotstayn 1997; Rotstayn et al. 2000). Cumulus convection is represented by the relaxed Arakawa-Schubert formulation of Moorthi and Suarez (1992).

Surface conditions at all island grid cells are computed by the GFDL land model (LM2), which includes soil sensible and latent heat storage, groundwater storage, and stomatal resistance. The surface vegetation is fixed as "broadleaf/needleleaf trees" and the soil type is "coarse/medium/fine mix." Surface fluxes are computed using Monin-Obukhov similarity theory. We do not use the AM2.1 gravity wave drag and "orographic roughness" parameterizations because our numerical resolution is adequate to capture the simple smooth topography.

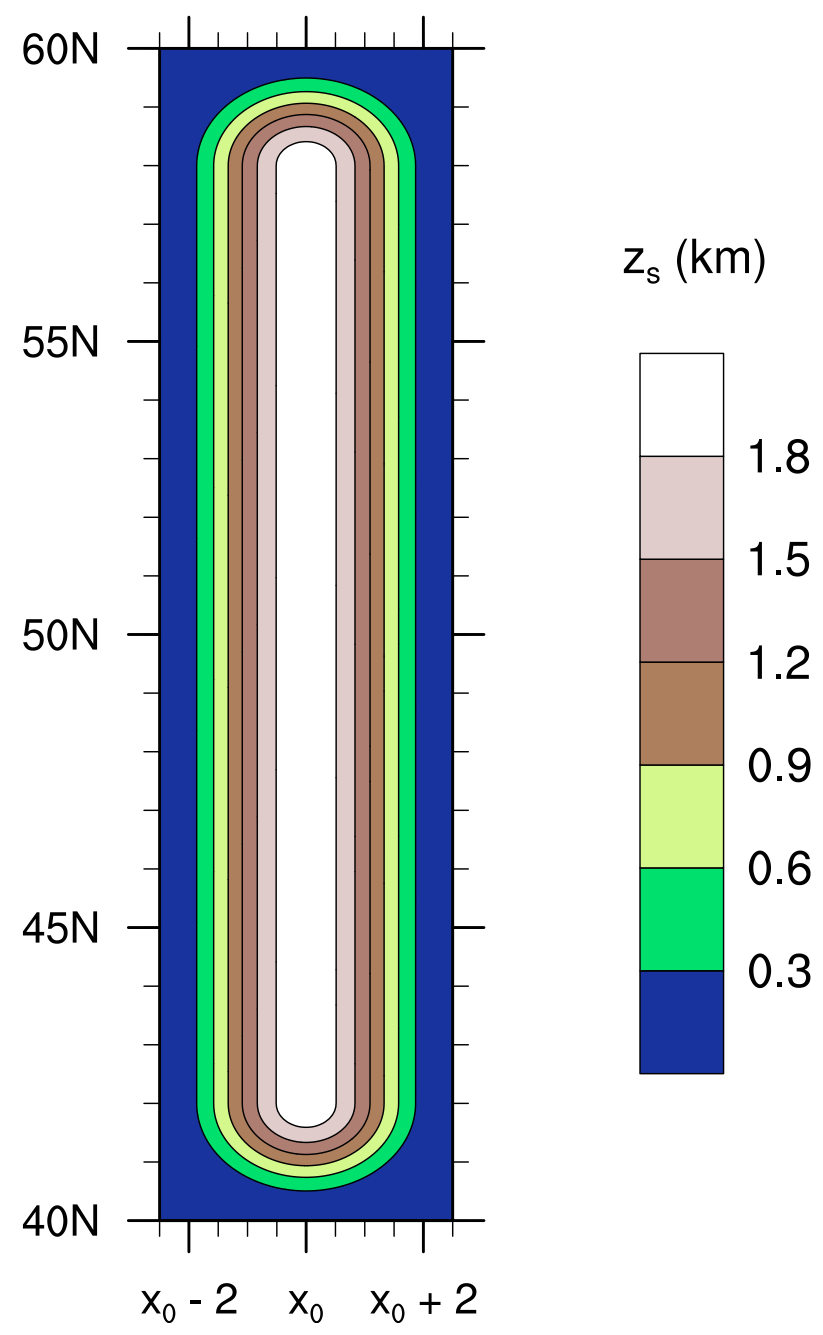

FIG. 1. The idealized topography for each island. Horizontal dimensions are in degrees of latitude and longitude; $x_{0}=45^{\circ}, 135^{\circ}$, $225^{\circ}$, or $315^{\circ}$ is the central longitude of an island.

The concentrations of all greenhouse gases except $\mathrm{CO}_{2}$ are fixed at climatological means, and the radiative effects of aerosols are not considered in these simulations so as to avoid unnecessary complexity. Solar radiation is fixed at its annual mean value, with no seasonal or diurnal cycle. Such perpetual annual mean conditions facilitate the use of a single relatively shallow ( $2.4 \mathrm{~m}$ deep) mixedlayer ocean that comes rapidly into equilibrium with $\mathrm{CO}_{2}$-induced changes in the radiative forcing. Sea ice is neglected in these simulations for simplicity.

All simulations are run for $20 \mathrm{yr}$ in total. The first $10 \mathrm{yr}$, which are more than adequate to spin up to the new climatic equilibrium, are discarded, and the last $10 \mathrm{yr}$ of data are used for our analysis. Most of our investigation is focused on a pair of simulations with mountains between $40^{\circ}-60^{\circ} \mathrm{N}$. In one member of the pair, the concentration of $\mathrm{CO}_{2}$ in the atmosphere is 


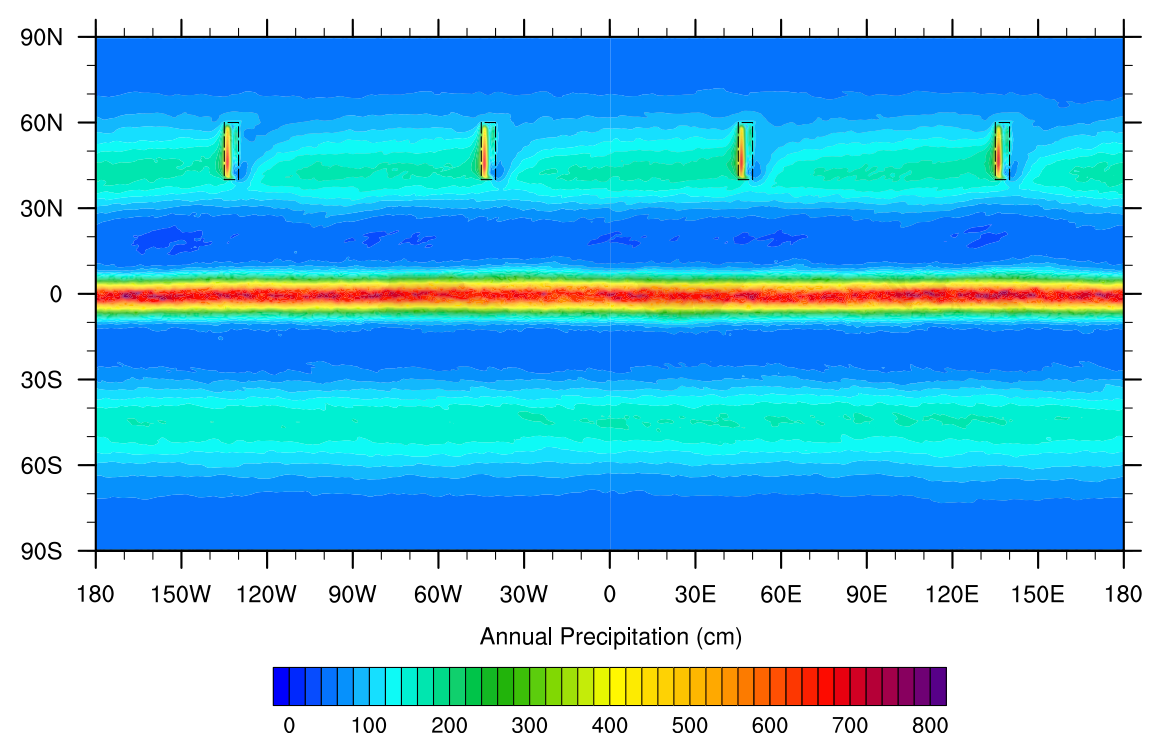

FIG. 2. Mean annual precipitation in simulation M1.

$330 \mathrm{ppm}$, corresponding to the $\mathrm{CO}_{2}$ level of 1970 s (referred to as experiment M1 hereafter), whereas in the other it is $660 \mathrm{ppm}$ (referred to as M2). Results from a second pair of experiments, with mountains between $35^{\circ}$ and $55^{\circ} \mathrm{N}$ (named $\mathrm{M}^{\prime}$ and $\mathrm{M} 2^{\prime}$ ) will also be discussed briefly. The third and final pair of 10-yr 330- and 660ppm simulations are for pure aquaplanet conditions (without any islands) and will be referred to as $\mathrm{A} 1$ and A2, respectively.

\section{Model climatology}

\section{a. Mean precipitation}

The mean annual precipitation in experiment M1 is shown in Fig. 2; not surprisingly there is heavy precipitation on the western side of each mountain range and much drier conditions on the leeward side. The annual western-side precipitation in M1 ranges between 400 and $700 \mathrm{~cm}$, which is roughly comparable to the 300 $500 \mathrm{~cm} \mathrm{yr}^{-1}$ observed on the windward side of the Olympic Mountains of Washington (Minder et al. 2008).

Figure $3 \mathrm{a}$ plots the zonal-mean precipitation as a function of latitude for simulations M1, M2, A1, and A2. Comparing A1 with M1 and A2 with M2, it is apparent that the mountains make only a modest change in the zonally averaged precipitation, slightly increasing the maximum and shifting the entire distribution a little toward the equator. Doubling the $\mathrm{CO}_{2}$ concentration causes a $2.56-\mathrm{K}$ increase in the global mean surface temperature between $\mathrm{M} 1$ and $\mathrm{M} 2$, and a $2.35-\mathrm{K}$ increase between $\mathrm{A} 1$ and $\mathrm{A} 2$. In both pairs of simulations, the increase in $\mathrm{CO}_{2}$ produces a $2^{\circ}-3^{\circ}$ northward shift and a very slight increase in the magnitude of the zonalmean midlatitude rain maximum. This shift is due to a poleward shift in the midlatitude storm tracks, which is a robust feature of circulation changes in most twentyfirst-century climate simulations (Yin 2005).

In contrast to the behavior of the zonal mean, doubling the $\mathrm{CO}_{2}$ leads to a substantial increase in precipitation over the western side of the mountains (Fig. 3b), increasing the maximum annually averaged precipitation by as much as $140 \mathrm{~cm} \mathrm{yr}^{-1}$ at $52^{\circ} \mathrm{N}$. The local increases are particularly pronounced between $48^{\circ}$ and $58^{\circ} \mathrm{N}$, whereas they are small or even negative along the southern part of the ridge between $40^{\circ}$ and $45^{\circ} \mathrm{N}$.

The global mean hydrological sensitivity, defined as the percentage change in precipitation per degree of global-mean surface warming, is $1.6 \%$ and $1.5 \% \mathrm{~K}^{-1}$ for the $\mathrm{M}$ and $\mathrm{A}$ simulations, respectively; these values are similar to those obtained in many other climate models (Held and Soden 2006). The latitudinal variation in the zonal-mean hydrological sensitivity (again defined with respect to the global-mean surface warming) is plotted for the band occupied by the mountains in Fig. 4. The presence of mountains has only a small impact on the zonal mean hydrological sensitivity, which increases with latitude from $-3 \%$ to $7 \% \mathrm{~K}^{-1}$, but the local response over the western slopes of the ridges is much larger, ranging from $-6 \%$ to $14 \% \mathrm{~K}^{-1}$, between $40^{\circ}$ and $58^{\circ} \mathrm{N}$. Precipitation near the northern end of the mountains increases at twice the $\mathrm{CC}$ scaling, which given that the global-mean surface temperature rises by $2.56 \mathrm{~K}$, corresponds to a very substantial $36 \%$ increase in the precipitation between M1 and M2. Some care must be taken 

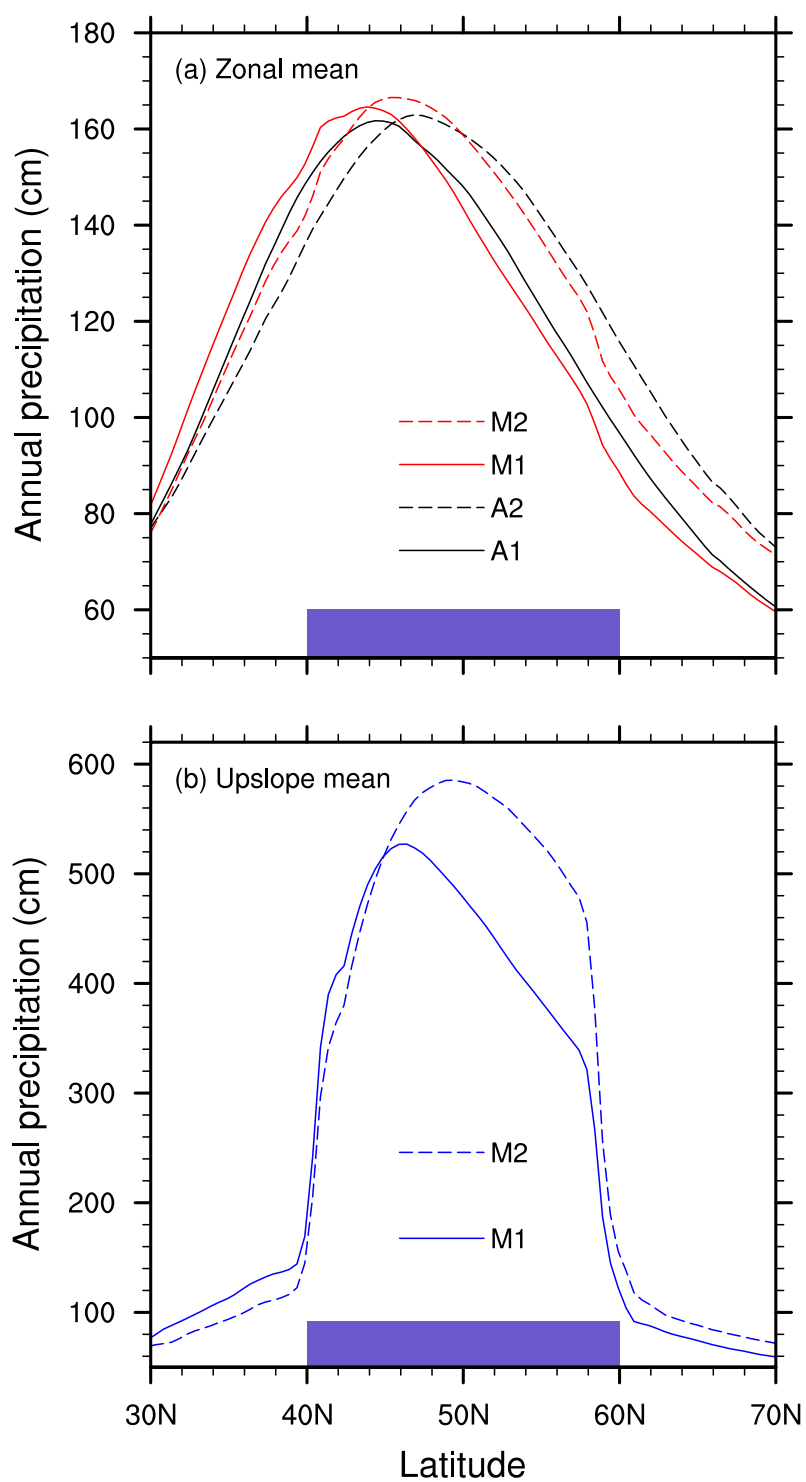

FIG. 3. Latitudinal dependence of the (a) zonal mean annual precipitation for the mountainous and aquaplanet simulations and (b) annual precipitation averaged over just the cells in north-south bands along the western sides of the four mountains. Blue bars along the abscissa indicate the latitudinal span of the mountains.

when interpreting the values obtained for hydrological sensitivity south of $45^{\circ} \mathrm{N}$ since, as shown in Fig. 3b, there is a very strong north-south gradient in precipitation in this region and large sensitivities are produced by small latitudinal shifts in the precipitation pattern.

The western-side hydrological sensitivity for simulations $\mathrm{M} 1^{\prime}$ and $\mathrm{M} 2^{\prime}$, with mountains between $35^{\circ}$ and $55^{\circ} \mathrm{N}$, is compared in Fig. 5 with the sensitivity for M1 and $\mathrm{M} 2$, which have ridges between $40^{\circ}$ and $60^{\circ} \mathrm{N}$. In both cases there is a reduction in sensitivity and in total precipitation within $2^{\circ}$ of the northern end of the mountains

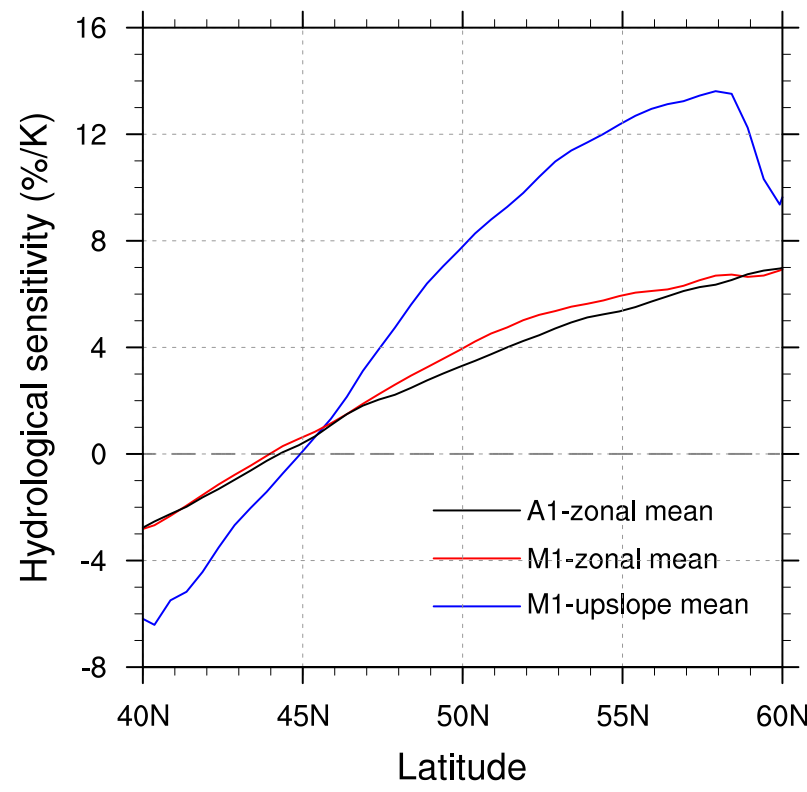

FIG. 4. Latitudinal dependence of the hydrological sensitivity of the annual precipitation averaged around the full latitude band in simulations M1 (red) and A1 (black), or averaged only over the western side of the mountains in simulation M1 (blue).

as the flow experiences less orographic ascent and more lateral deflection around the end of the mountain. The north-south gradient in the western-side hydrological sensitivity as a function of distance from the northern end of the mountain is similar in both cases, suggesting that the processes responsible for this gradient are not sensitive to the precise location of the barrier. The hydrological sensitivities averaged over the entire western side are nevertheless quite different for these two cases; for the $35^{\circ}-55^{\circ} \mathrm{N}$ mountain this sensitivity is $1.6 \% \mathrm{~K}^{-1}$, but it is $5 \% \mathrm{~K}^{-1}$ in the $40^{\circ}-60^{\circ} \mathrm{N}$ case.

\section{b. Precipitation intensity}

To estimate changes in the intensity of orographic precipitation, all precipitation events over the western slopes were sorted into four classes based on the precipitation accumulated over each hour: negligible events $\left(<0.02 \mathrm{~mm} \mathrm{~h}^{-1}\right)$, light events $\left(0.02-1.0 \mathrm{~mm} \mathrm{~h}^{-1}\right)$, moderate events $\left(1.0-4.0 \mathrm{~mm} \mathrm{~h}^{-1}\right)$, and heavy/extreme events $\left(\geq 4.0 \mathrm{~mm} \mathrm{~h}^{-1}\right)$. The $4.0 \mathrm{~mm} \mathrm{~h}^{-1}$ threshold for the heavy/extreme events approximates the 99th percentile of the orographic precipitation intensity in the M1 simulation. To reveal the substantial north-south variations in precipitation intensity, the western side of each mountain was divided to five east-west bands, each of which spans $4^{\circ}$ in latitude. The frequency and average intensity for each precipitation class in each band is compared for simulations M1 and M2 in Fig. 6. 


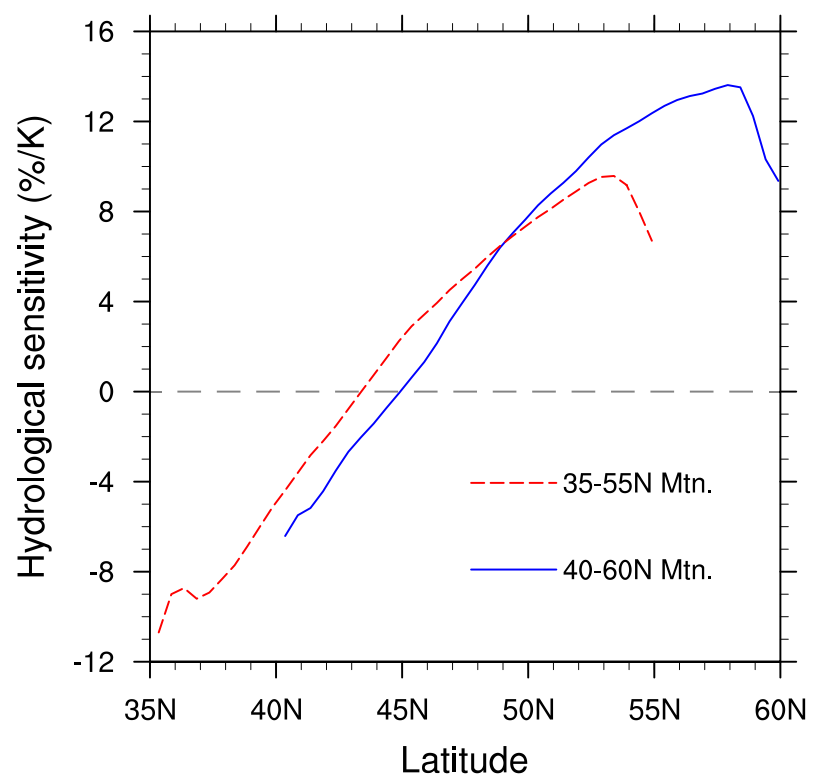

FIG. 5. Latitudinal dependence of the hydrological sensitivity of the annual precipitation averaged over the western side of the mountains from simulations M1' and M2' (red dashed) or M1 and M2 (blue solid).

Figure 6a shows the percentage of time during which negligible or no precipitation occurred. Clearly there were significant changes in this quantity in the warmer climate, with the percentage of dry days increasing from $15 \%$ to $20 \%$ in the southernmost band but decreasing from $29 \%$ to $22 \%$ in the northernmost band. Comparing all four panels in Fig. 6, it is apparent that the warmer climate skews toward heavier precipitation events. In particular, the frequency of heavy/extreme events is doubled in the three northern bands. The mean intensities of the heavy/ extreme events also increase at all latitudes.

Most of the accumulated precipitation (reflecting the product of intensity and frequency) in each of the five bands is produced by events in either the light or the moderate precipitation classes, each of which provides roughly $45 \%$ of the total. The rest is contributed by heavy/extreme events. As the climate warms, the portion from the moderate and the heavy/extreme classes increases, while that from light precipitation decreases.

To quantify the importance of changes in the frequency of rainy hours on the annual accumulated precipitation, let an overbar denote an average over those times of the year when nonnegligible precipitation is occurring-which is defined in the context of Fig. 6 as those hours when the precipitation intensity averaged across the four cells in an east-west line ascending the western slope of the underlying mountain exceeds $0.02 \mathrm{~mm} \mathrm{~h}^{-1}$. Let $\tau$ be the average number of hours in one year during which such precipitation occurs and $\bar{P}$ be the average precipitation rate during those events. Since the contribution to the annual average accumulated precipitation $A_{p}$ from those events with average western-slope intensities less than $0.02 \mathrm{~mm} \mathrm{~h}^{-1}$ is less than about $0.5 \%$ of the total, to good approximation $A_{p}=\bar{P} \tau$ and the fractional changes in each of these quantities because of increased $\mathrm{CO}_{2}$ satisfy

$$
\frac{\delta A_{p}}{A_{p}} \approx \frac{\delta \bar{P}}{\bar{P}}+\frac{\delta \tau}{\tau} .
$$

As shown in Fig. 7a, $\delta \bar{P} / \bar{P}$ makes the larger contribution to $\delta A_{p} / A_{p}$ at all latitudes north of $45^{\circ}$. The contribution from $\delta \tau / \tau$ is nevertheless quite significant: it dominates the drying at the south end of the ridge and at least half the size of $\delta \bar{P} / \bar{P}$ in the north. The increase in the number of rainy hours in the north, and the decrease in the south, is consistent with the northward shift of the storm track.

Further verification of a northward shift in storminess is provided by examining the sensitivity of the zonally averaged vertical velocity variance $\delta \omega^{\prime 2} / \omega^{\prime 2}$ (in units of percent per kelvin of surface warming). The values of $\omega^{\prime 2}$ are mass-weighted vertical averages between 850 and $600 \mathrm{hPa}$ and 2-8-day bandpass filtered; they reveal the influence of transient synoptic-scale disturbances on vertical velocities in the layer typically occupied by orographic clouds. As shown in Fig. $7 \mathrm{~b}, \delta \omega^{\prime 2} / \omega^{\prime 2}$ decreases by $2 \% \mathrm{~K}^{-1}$ over the southern end of the mountains; it drops to zero around $47^{\circ} \mathrm{N}$, and it increases by $5 \% \mathrm{~K}^{-1}$ over the northern end of the range. These variations are similar to those in $\delta \tau / \tau$, supporting the interpretation that the change in the annually averaged frequency of rainy hours is driven by changes in synoptic-scale storminess.

\section{c. Water vapor transport}

Let $\langle\cdot\rangle$ denote the annual mean averaged over all hours, including those with no rain. The difference between the annual mean precipitation rate $\langle P\rangle$ and the annual mean evaporation rate $\langle E\rangle$ averaged over the latitude band between $40^{\circ}$ and $60^{\circ} \mathrm{N}$ is given by the annual mean convergence of water flux into the band. In AM2.1, the total water flux is the sum of the fluxes of water vapor, cloud liquid water, and cloud ice (there are no prognostic precipitation fields). The cloud water fluxes are much smaller than the water vapor fluxes and have only a trivial influence on the water balance in the band. The terms in the annual average water budget for this band are listed in Table 1 for simulations M1, M2, $\mathrm{A} 1$, and $\mathrm{A} 2$. The values of $\langle P\rangle$ and $\langle E\rangle$ are accumulated at every model time step, whereas the water vapor fluxes are available only once per day. As a consequence of the coarse time resolution in the water vapor flux calculation (and the neglect of cloud water fluxes), the budget 

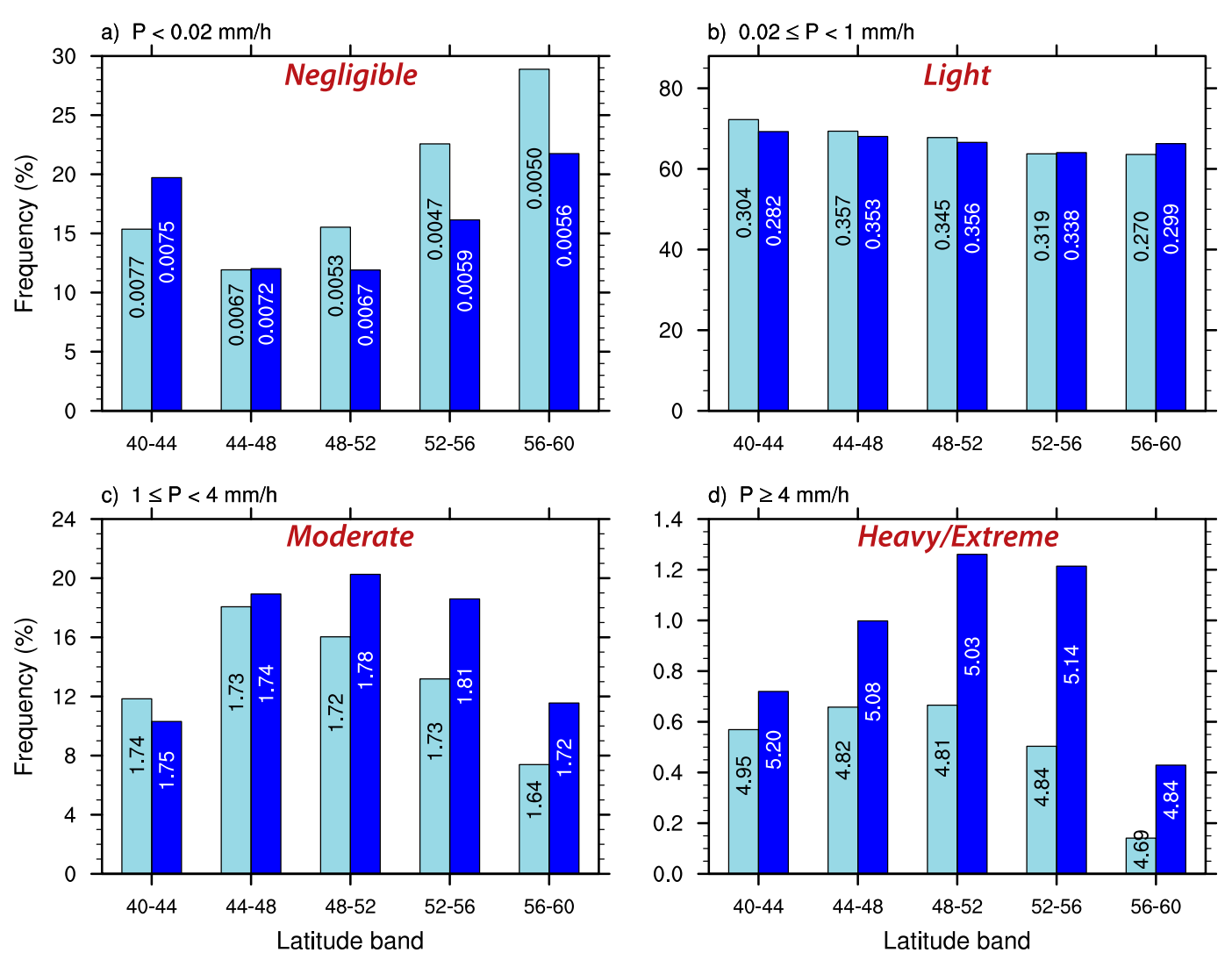

FIG. 6. Frequency as a function of latitude for (a) negligible, (b) light, (c) moderate, and (d) heavy/extreme precipitation events over the western slopes of the mountains. Values for simulations M1 and M2 are shown in light and dark blue, respectively. The mean intensity $\left(\mathrm{mm} \mathrm{h}^{-1}\right)$ for each class appears in the corresponding vertical bar.

does not close perfectly, but the residual is less than $1 \%$ of the largest term $\langle P\rangle .{ }^{1}$ In the doubled $\mathrm{CO}_{2}$ cases, water vapor transport from the tropics increases by about $12 \%$ and becomes almost equal to the second-largest term: evaporation within the band. Aside from a tendency to modestly reduce the evaporative fluxes, the mountains have little influence on the individual terms in the zonally averaged water budget. The average hydrological sensitivity in the band between $40^{\circ}$ and $60^{\circ} \mathrm{N}$ is $2.6 \% \mathrm{~K}^{-1}$ for the cases with mountains and $2.2 \% \mathrm{~K}^{-1}$ for the aquaplanet simulations.

The mountains do reduce the annual averaged eastward moisture fluxes impinging on their windward slopes. Table 2 compares the frequency with which zonal winds averaged between the surface and the height of the mountain at the upstream edge of the topography (i.e., $2.5^{\circ}$ west of the ridgeline) were at least $2 \mathrm{~m} \mathrm{~s}^{-1}$ in simulations $\mathrm{A} 1$ and $\mathrm{M} 1 .^{2}$ Also listed are the average

\footnotetext{
${ }^{1}$ Computed with four decimal places of precision.

${ }^{2}$ The $2 \mathrm{~m} \mathrm{~s}^{-1}$ threshold was imposed to avoid counting weak thermally driven upslope flows.
}

eastward moisture fluxes through a meridional cross section above the western foot of the mountains and the mean vertically integrated humidity for simulations M1 and $\mathrm{A} 1$ (again restricted to those cases with low-level eastward winds stronger than the $2 \mathrm{~m} \mathrm{~s}^{-1}$ threshold). The frequency and the strength of the eastward moisture flux increases greatly from north to south in both simulations A1 and M1. The mountains do not significantly influence the frequency of eastward flow, but they have a strong impact on the moisture fluxes, which are reduced between simulations A1 and M1 by roughly $30 \%$ in the middle and southern sections of the mountain. This reduction is entirely a result of a reduction in the strength of the eastward flow, because the upstream humidity is generally greater in simulation M1, as indicated in the last two columns of Table $2 .^{3}$

Figure 8 illustrates how the water budget for the windward slopes changes between simulations M1 and

\footnotetext{
${ }^{3}$ The zonally averaged evaporation rates are similar in A1 and M1 because the decreases in the surface westerlies in M1 are compensated by increased meridional winds that keep the zonally averaged surface wind speed roughly constant.
} 

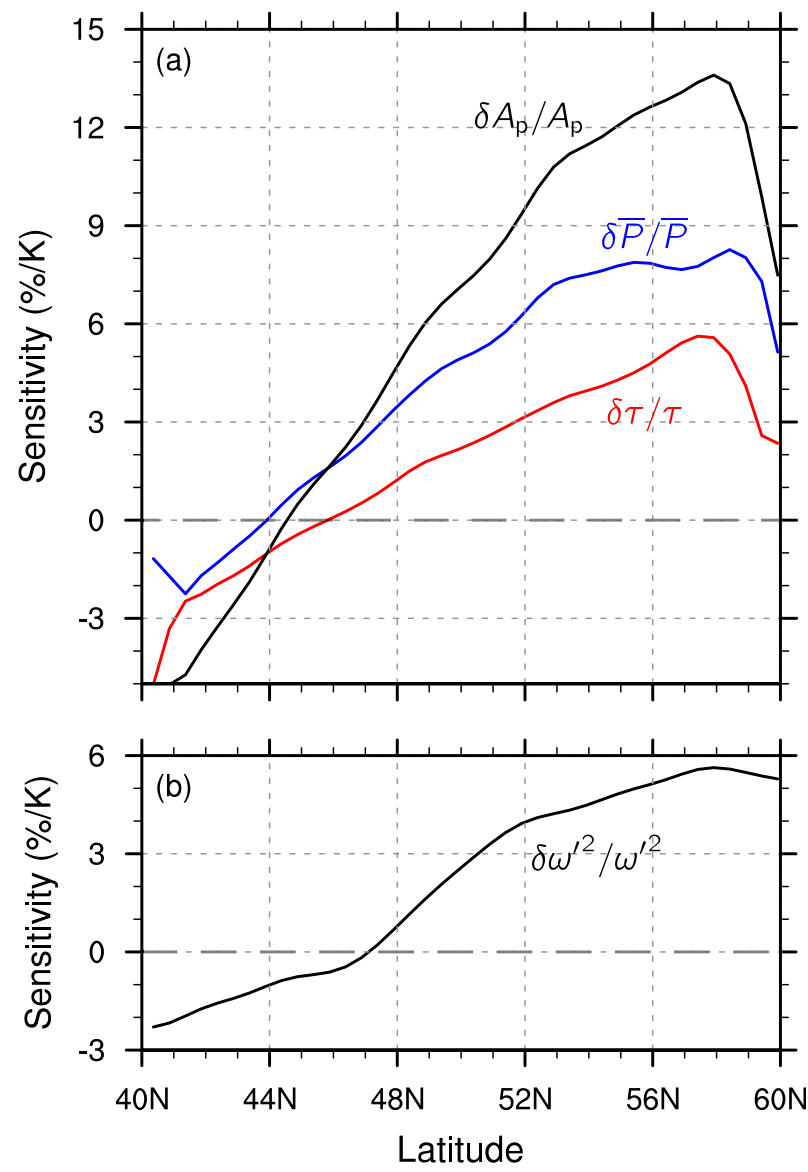

FIG. 7. (a) Latitudinal dependence of the sensitivity $\left(\% \mathrm{~K}^{-1}\right)$ in the annual accumulated precipitation $\delta A_{p} / A_{p}$, the averaged precipitation rate $\delta \bar{P} / \bar{P}$, and the annual averaged number of hours during which precipitation occurs $\delta \tau / \tau$. All three quantities are averaged over the western sides of the mountains. (b) Latitudinal dependence of the sensitivity $\left(\% \mathrm{~K}^{-1}\right)$ in the mass-weighted 850-600-hPa vertical average of the 2-8-day band-passed vertical velocity variance. Values are zonally averaged around a full latitude circle.

M2. As in Table 2, these values are broken into latitude bands for cases where the average low-level winds at the western edge of each band exceed $2 \mathrm{~m} \mathrm{~s}^{-1}$. The cases making up the average therefore vary among the latitude bands and, thus, the north-south water vapor fluxes do not match across the band boundaries. In both simulations, the largest term is the eastward flux impinging on the mountains; this flux increases substantially from north to south and also increases with increasing $\mathrm{CO}_{2}$. The incoming fluxes are primarily balanced by outgoing eastward fluxes at the ridge crest, whose latitudinal variation is also substantial. The north-south water vapor flux divergence removes a modest amount of water from each band, except in the southernmost band where it matches (M1) or exceeds (M2) the precipitation.
TABLE 1 . Water budget for the latitude band $40^{\circ}-60^{\circ} \mathrm{N}$ for simulations M1, M2, A1, and A2. Entries are the annual-averaged area-integrated precipitation rate $\langle P\rangle$, evaporation rate $\langle E\rangle$, and water vapor fluxes across the southern and northern boundaries (units are $10^{9} \mathrm{~kg} \mathrm{~s}^{-1}$ ).

\begin{tabular}{lcccc}
\hline \hline & $\langle P\rangle$ & $\langle E\rangle$ & $\left\langle\right.$ Flux $\left.40^{\circ} \mathrm{N}\right\rangle$ & $\left\langle\right.$ Flux $\left.60^{\circ} \mathrm{N}\right\rangle$ \\
\hline M1 & 2.53 & 1.48 & 1.33 & 0.31 \\
M2 & 2.70 & 1.57 & 1.52 & 0.41 \\
A1 & 2.56 & 1.52 & 1.34 & 0.33 \\
A2 & 2.69 & 1.60 & 1.51 & 0.44 \\
\hline
\end{tabular}

Evaporation makes an almost negligible contribution to the total budget. The water budgets diagrammed in Fig. 8 are not annual means, and therefore need not close exactly. All the residuals are negative, ranging between $-7 \%$ and $-1 \%$ of the eastward flux into the band. The residual water balances for the remaining cases not included in Fig. 8 are all positive; the mountains act as a sink of water during the rainy periods and as a water source through evaporation when it is not raining.

The "drying ratio" (DR) is a measure of the efficiency with which mountains remove moisture from the air. It is defined by Smith et al. (2003) as the precipitation divided by the water vapor flux into some control volume, or equivalently one minus the ratio of outgoing to incoming water vapor flux. Kirshbaum and Smith (2008) evaluated the drying ratio in idealized horizontally uniform flows impinging on an isolated mountain, but because nontrivial eastward moisture fluxes strike our mountains almost twice as often in the south as in the north (Table 2), it is difficult to define a meaningful drying ratio for the entire ridge. Instead we compute DR as a function of latitude band for simulations M1 and M2 in Table 3 using the same $>2 \mathrm{~m} \mathrm{~s}^{-1}$ low-level wind speed criterion imposed on the data in Fig. 8. The incoming and outgoing water vapor fluxes used to determine these DR include both the zonal and meridional components.

TABLE 2. Comparison of the water vapor flux at western boundaries of the five bands of the mountains in $\mathrm{M} 1$ and that of the corresponding areas in A1. The first two columns are the frequency $(\%)$ of the occurrence of eastward flux with low-level wind speeds greater than $2 \mathrm{~ms}^{-1}$ in $\mathrm{A} 1\left(f_{\mathrm{A} 1}\right)$ and $\mathrm{M} 1\left(f_{\mathrm{M} 1}\right)$. The middle two columns are the mean integrated eastward flux $\left(\mathrm{kg} \mathrm{s}^{-1}\right)$ through vertical surface bounding the western sides of each latitude band ( $F_{\mathrm{A} 1}$ and $F_{\mathrm{M} 1}$ for $\mathrm{A} 1$ and $\mathrm{M} 1$ respectively). The last two columns are the mean water vapor integrated over the same vertical boundaries $\left(\mathrm{kg} \mathrm{m}^{-2}\right)\left(Q_{\mathrm{A} 1}\right.$ and $\left.Q_{\mathrm{M} 1}\right)$.

\begin{tabular}{lccrccc}
\hline \hline & $f_{\mathrm{A} 1}$ & $f_{\mathrm{M} 1}$ & $F_{\mathrm{A} 1}$ & $F_{\mathrm{M} 1}$ & $Q_{\mathrm{A} 1}$ & $Q_{\mathrm{M} 1}$ \\
\hline $56^{\circ}-60^{\circ} \mathrm{N}$ & 38 & 42 & 6.0 & 5.3 & 13.3 & 14.3 \\
$52^{\circ}-56^{\circ} \mathrm{N}$ & 49 & 48 & 7.5 & 5.7 & 14.8 & 15.7 \\
$48^{\circ}-52^{\circ} \mathrm{N}$ & 60 & 59 & 9.4 & 6.5 & 16.5 & 17.3 \\
$44^{\circ}-48^{\circ} \mathrm{N}$ & 68 & 69 & 11.3 & 7.5 & 18.3 & 18.7 \\
$40^{\circ}-44^{\circ} \mathrm{N}$ & 72 & 78 & 12.9 & 9.0 & 20.0 & 19.9 \\
\hline
\end{tabular}



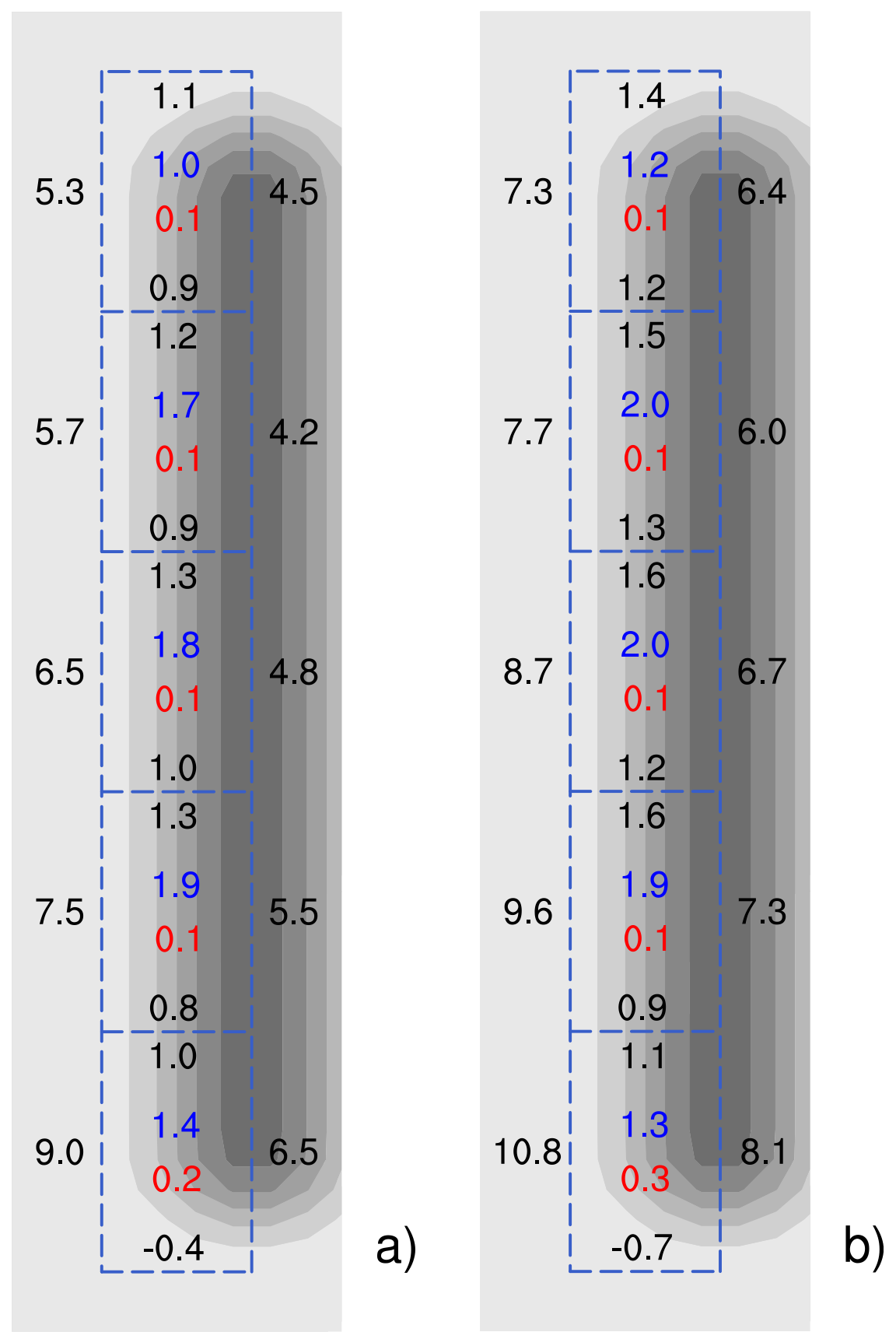

FIG. 8. Schematic illustration of the terms in the water balance for the five bands on the windward slope for simulations (a) M1 and (b) M2. Dashed lines show the extent of each budget volume; the latitude bands match those in Tables 2-4. Shading shows the topography. Blue numbers are precipitation, and red are evaporation. Black numbers are water vapor fluxes through the adjacent boundary. All values are averages for times with band-averaged eastward winds between the surface and $2 \mathrm{~km}$ greater than $2 \mathrm{~m} \mathrm{~s}^{-1}$. North-south fluxes are not continuous across the band boundaries because different sets of cases make up the average in each band.

Table 3 lists these drying ratios together with the mean upwind surface temperature in each band. The drying ratios are smallest near the northern and southern ends of the ridge, where the flow can easily deflect around the ends of the mountain. The drying ratios in the central three latitude bands are roughly $75 \%$ as large as the values obtained by Kirshbaum and Smith (2008) for flows at the same surface temperature impinging on 
TABLE 3. Mean surface temperature (K) and drying ratio for the western slopes of the mountains averaged over the indicated latitude bands in simulations M1 and M2.

\begin{tabular}{lcccc}
\hline \hline & $T_{\mathrm{M} 1}$ & $T_{\mathrm{M} 2}$ & $\mathrm{DR}_{\mathrm{M} 1}$ & $\mathrm{DR}_{\mathrm{M} 2}$ \\
\hline $56^{\circ}-60^{\circ} \mathrm{N}$ & 282.9 & 285.3 & 0.10 & 0.09 \\
$52^{\circ}-56^{\circ} \mathrm{N}$ & 284.3 & 286.7 & 0.19 & 0.17 \\
$48^{\circ}-52^{\circ} \mathrm{N}$ & 285.6 & 287.9 & 0.19 & 0.16 \\
$44^{\circ}-48^{\circ} \mathrm{N}$ & 286.9 & 289.2 & 0.18 & 0.14 \\
$40^{\circ}-44^{\circ} \mathrm{N}$ & 288.2 & 290.6 & 0.11 & 0.08 \\
\hline
\end{tabular}

a 3D Gaussian ridge about half the width of our mountain. Given the substantial differences in the details of our precipitation events and those simulated in Kirshbaum and Smith (2008), there is no reason to expect better quantitative agreement. As in both Kirshbaum and Smith (2008) and Cannon et al. (2012), DR in the central part of the range decreases with increasing temperature, both north to south along the ridge and within each latitude band when $\mathrm{CO}_{2}$ is doubled. Of course temperature is not the only determinant of DR; the temperature between $44^{\circ}$ and $48^{\circ} \mathrm{N}$ in $\mathrm{M} 1$ is greater than that between $52^{\circ}$ and $56^{\circ} \mathrm{N}$ in $\mathrm{M} 2$, but DR is smaller in the colder northern band.

One way to appreciate the importance of circulation changes in regulating the precipitation along each ridge is to contrast the actual changes in water vapor flux convergence with what would be expected if the circulation remained unchanged in a warmer world. Consider the same $4^{\circ}$-wide bands on the upwind slope identified in Fig. 8. The difference between the annual mean precipitation rate $\langle P\rangle$ and the annual mean evaporation rate $\langle E\rangle$ in each band is given by the annual mean total water flux convergence across the band. As argued in the "dry get drier" theory of precipitation changes in response to global warming (Held and Soden 2006; Scheff and Frierson 2012), if the velocities that define the circulation are unchanged, then the fractional changes in total water flux convergence must be equal to the fractional changes in the water content of the air, which should follow the CC scaling.

Table 4 gives the sensitivities to the change in global mean surface temperature of $\langle P\rangle,\langle E\rangle$, and $\langle P\rangle-\langle E\rangle$ averaged over the western slope of the ridge within each latitude band. As previously illustrated in Fig. 3, the systematic south-north increase in $\delta\langle P\rangle /\langle P\rangle$ is quite substantial. The south-north increase in $\delta(\langle P\rangle-\langle E\rangle) /$ $(\langle P\rangle-\langle E\rangle)$ is, however, even larger; it ranges from $-5.7 \% \mathrm{~K}^{-1}$ in the south to $15.4 \% \mathrm{~K}^{-1}$ in the north, and it must be balanced by identical changes in total water flux convergence. But the sensitivity of the annual mean column-integrated water vapor ${ }^{4}$ above the western slope

\footnotetext{
${ }^{4}$ The column-integrated total water was not archived in these simulations and is not available, but simulations of similar cases show that $\int\left\langle q_{v}\right\rangle$ differs from the column integrated total water by less than $5 \%$.
}

TABLE 4. Sensitivities with respect to the global mean surface temperature in the annual mean: precipitation $\langle P\rangle$, evaporation $\langle E\rangle$, their difference, the column-integrated water vapor $\int\left\langle q_{v}\right\rangle$, and the column-integrated water vapor that would be produced by the simulated temperature changes if the relative humidity remained constant (CC). (All quantities are averaged over the western slopes of the four mountains and over the indicated latitude bands, and are expressed in units of $\% \mathrm{~K}^{-1}$.)

\begin{tabular}{lrcccc}
\hline \hline & $\frac{\delta\langle P\rangle}{\langle P\rangle}$ & $\frac{\delta\langle E\rangle}{\langle E\rangle}$ & $\frac{\delta(\langle P\rangle-\langle E\rangle)}{\langle P\rangle-\langle E\rangle}$ & $\frac{\delta \int\left\langle q_{v}\right\rangle}{\int\left\langle q_{v}\right\rangle}$ & $\mathrm{CC}$ \\
\hline $56^{\circ}-60^{\circ} \mathrm{N}$ & 12.9 & 2.2 & 15.4 & 9.8 & 8.4 \\
$52^{\circ}-56^{\circ} \mathrm{N}$ & 11.8 & 1.7 & 13.0 & 9.9 & 8.6 \\
$48^{\circ}-52^{\circ} \mathrm{N}$ & 7.8 & 3.7 & 8.3 & 9.4 & 8.7 \\
$44^{\circ}-48^{\circ} \mathrm{N}$ & 1.9 & 4.7 & 1.5 & 8.6 & 8.9 \\
$40^{\circ}-44^{\circ} \mathrm{N}$ & -3.6 & 3.4 & -5.7 & 7.5 & 9.1 \\
\hline
\end{tabular}

in each latitude band $\delta \int\left\langle q_{v}\right\rangle / \int\left\langle q_{v}\right\rangle$ (fourth column in Table 4) is very different from $\delta(\langle P\rangle-\langle E\rangle) /(\langle P\rangle-\langle E\rangle)$, implying that the changes in the water vapor flux convergence are dominated by changes in the velocity field. Instead of matching $\delta(\langle P\rangle-\langle E\rangle) /(\langle P\rangle-\langle E\rangle)$, the water vapor sensitivity $\delta \int\left\langle q_{v}\right\rangle / \int\left\langle q_{v}\right\rangle$ roughly approximates that predicted by the Clausius-Clapeyron equation from the changes in the temperatures within each column under the assumption of constant relative humidity (last column of Table 4).

\section{A simple diagnostic model for orographic precipitation}

It is difficult to develop a simple conceptual understanding of the key factors responsible for the changes in orographic precipitation by directly examining every term in the diagnostic parameterizations of precipitation in the AM2.1 simulations. The parameterization of convective precipitation is highly idealized and not tuned to describe the convection triggered by mountains. The grid-resolved (hereafter referred to as "stratiform") precipitation parameterization also includes many elements (such as a parameterization of the autoconversion threshold to account for subgrid-scale variations in cloudiness) that are not typically present in mesoscale atmospheric models with prognostic equations for the precipitating microphysical variables. The physical processes responsible for the stratiform orographic precipitation in these simulations can, therefore, be more clearly understood using the prognostic wind, temperature, and moisture fields from the AM2.1 simulations to drive a physically motivated diagnostic model. As will be demonstrated, the precipitation from this diagnostic model gives a good approximation to the actual stratiform orographic precipitation generated by the AM2.1 simulations.

Our diagnostic model of stratiform orographic precipitation is formulated as follows. Consider an air parcel 
traversing a grid cell over the windward side of a mountain over the time interval $\delta t=\Delta x / u$, where $u$ is the crossridge component of the horizontal velocity in the cell. As parcel crosses the cell, it is lifted through a vertical distance $z^{* *}=w \delta t$, where $w$ is the vertical velocity in that cell. Let $z^{*}$ (defined by formulas in appendix A) denote the lifted condensation level for the air in the same grid cell (i.e., the vertical distance it must be lifted to reach saturation). Then if $z^{* *}>z^{*}$, the condensation occurring as the parcel passes through the cell is

$$
\delta q=\int_{z^{*}}^{z^{* *}} \frac{d q_{s}}{d z} d z \approx\left(z^{* *}-z^{*}\right) \frac{d q_{s}}{d z},
$$

where $q_{s}$ is the saturation specific humidity. The condensation rate within the cell is therefore

$$
\frac{\delta q}{\delta t}=\frac{u}{\Delta x}\left(z^{* *}-z^{*}\right) \frac{d q_{s}}{d z},
$$

Note that if the air in the cell is already saturated, (4) simplifies to the familiar expression

$$
\frac{\delta q}{\delta t}=w \frac{d q_{s}}{d z} .
$$

Assuming that the all condensate forming in each vertical column immediately falls to surface, the diagnosed precipitation rate at the surface is

$$
\begin{aligned}
\mathcal{P} & =\sum_{k} \rho_{k}\left(-\frac{\delta q}{\delta t}\right)_{k} \Delta z_{k} \\
& =-\sum_{k} \frac{u_{k}}{g \Delta x}\left(z_{k}^{* *}-z_{k}^{*}\right)\left(\frac{d q_{s}}{d z}\right)_{k}|\Delta p|_{k},
\end{aligned}
$$

where $k$ is the vertical-coordinate index and $g$ is the gravitational constant.

The preceding formulation is particular to stratiform orographic precipitation (as opposed to general stratiform precipitation) only in that $\delta t$ is the advective time scale for an air parcel traveling perpendicular to the ridgeline. To ensure that this orographic precipitation model is only applied in appropriate meteorological conditions, it is only evaluated over the western slopes of each ridge and $u_{k}$ is set to zero whenever it is less than $1 \mathrm{~m} \mathrm{~s}^{-1}$. As detailed in appendix $\mathrm{A}$, the moist pseudoadiabatic lapse rate of saturation specific humidity (hereafter referred to as the lapse rate of saturation specific humidity) $\gamma_{s}$ is

$$
\gamma_{s}=-\frac{d q_{s}}{d z}=q_{s}\left(\frac{L \Gamma_{m}}{R_{v} T^{2}}-\frac{g}{R_{d} T}\right) \equiv \frac{q_{s}}{H_{q_{s}}},
$$

which defines the scale height of saturation specific humidity $H_{q_{s}}$.
To make the subsequent analysis more concise, define the discrete approximation to the vertical integral operator as

$$
\mathcal{I}(\cdot)=\frac{1}{g \Delta x} \sum_{k}(\cdot)_{k}|\Delta p|_{k}
$$

and let

$$
u_{\dagger}=\left\{\begin{array}{ll}
u, & \text { if } u>1 \\
0, & \text { otherwise }
\end{array} \text { and } d_{z}=\max \left(z^{* *}-z^{*}, 0\right) .\right.
$$

Then the diagnostic estimate of orographic precipitation (5) may be written

$$
\mathcal{P}=\mathcal{I}\left(u_{\dagger} d_{z} \gamma_{s}\right) .
$$

The complete dynamical fields were output from the full simulations only once per day. As a consequence, our diagnostic evaluation of the annual accumulated rainfall $\mathcal{P}_{a}$ is performed at coarser time resolution than that used to accumulate the full model's stratiform and convective precipitation, which were collected at every time step. Nevertheless, as shown in Fig. 9a, $\mathcal{P}_{a}$ matches the annual mean stratiform precipitation on western side of the mountains in simulation M1 very well. As apparent from the difference between the "total" and the stratiform curves in Fig. 9a, the convective parameterization also makes an important contribution to the total precipitation. Because it is produced by a parameterization not specifically tuned for the influence of orography, we leave the task of providing thorough physical insight into the factors governing the changes in the convective precipitation over the mountains to future study. Nevertheless, it is interesting to note that, as shown in Fig. 9b, the hydrological sensitivity over the western slope due to increased $\mathrm{CO}_{2}$ is very similar when evaluated using our diagnostic model or either the stratiform or the total precipitation from the full M1 and M2 simulations. In the following section we investigate the factors responsible for the hydrological sensitivity of the stratiform precipitation indicated in Fig. $9 \mathrm{~b}$.

\section{Understanding the changes in stratiform orographic precipitation}

\section{a. Use of annual averaged values}

As before, let an overbar denote the annual average over those times when nonnegligible precipitation is occurring. Letting primes denote fluctuations about this annual average, each variable in (9) can be decomposed as 

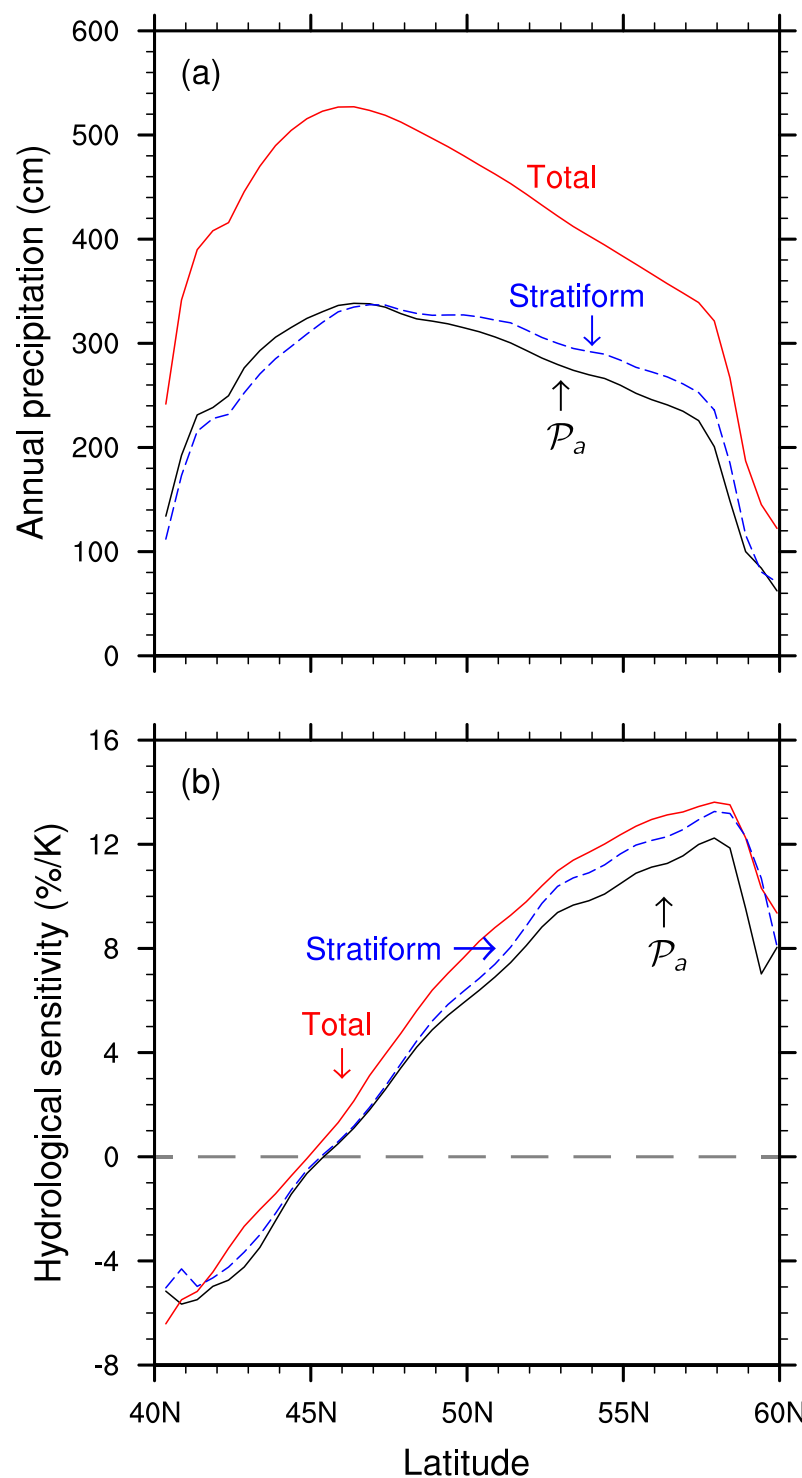

FIG. 9. Latitudinal dependence of (a) the accumulated westernside stratiform precipitation, the total (stratiform plus convective, $A_{p}$ ) and $\mathcal{P}_{a}$ diagnosed from (9) for simulation M1; (b) fractional changes in stratiform, total, and diagnosed precipitation as $\mathrm{CO}_{2}$ concentration is doubled from M1 to M2.

$$
u_{\dagger}=\bar{u}_{\dagger}+u_{\dagger}^{\prime}, \quad d_{z}=\bar{d}_{z}+d_{z}^{\prime}, \quad \text { and } \quad \gamma_{s}=\bar{\gamma}_{s}+\gamma_{s}^{\prime} .
$$

The annual averaged precipitation intensity from the diagnostic model satisfies

$$
\begin{aligned}
\overline{\mathcal{P}} & =\mathcal{I}\left(\overline{u_{\dagger} d_{z} \gamma_{s}}\right) \\
& =\mathcal{I}\left(\bar{u}_{\dagger} \bar{d}_{z} \bar{\gamma}_{s}\right)+\mathcal{I}\left(\bar{u}_{\dagger} \overline{d_{z}^{\prime} \gamma_{s}^{\prime}}+\bar{d}_{z} \overline{\gamma_{s}^{\prime} u_{\dagger}^{\prime}}+\bar{\gamma}_{s} \overline{u_{\dagger}^{\prime} d_{z}^{\prime}}+\overline{u_{\dagger}^{\prime} d_{z}^{\prime} \gamma_{s}^{\prime}}\right) .
\end{aligned}
$$

Define the contribution to $\overline{\mathcal{P}}$ from the annual averages of the individual variables as $M=\mathcal{I}\left(\bar{u}_{\uparrow} \bar{d}_{z} \bar{\gamma}_{s}\right)$ and denote

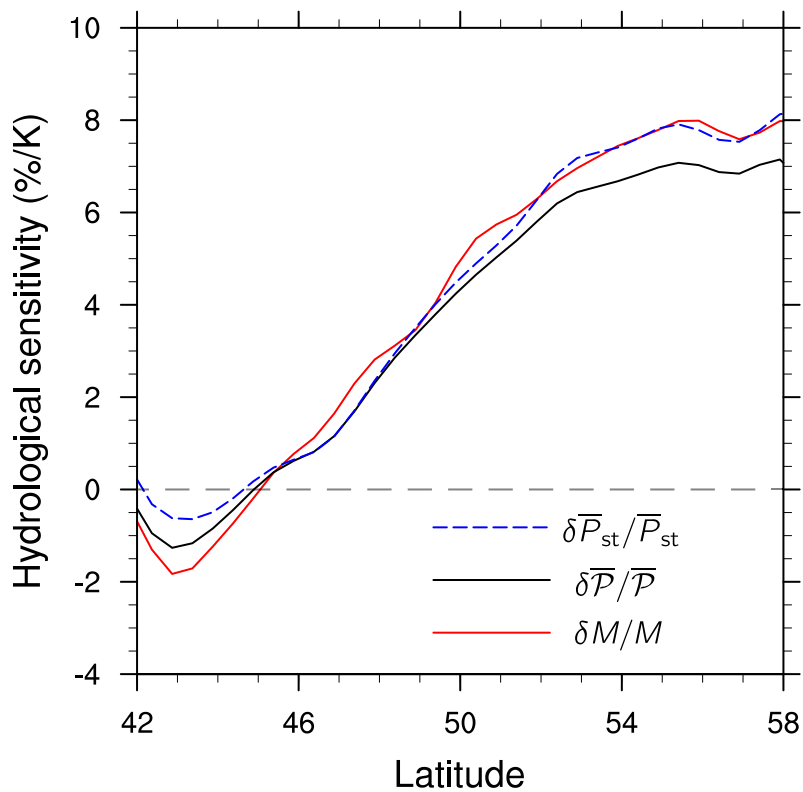

FIG. 10. Hydrological sensitivity of the western-side precipitation rate for the GCM large scale cloud scheme $P_{\text {st }}$, the full diagnostic precipitation model $\overline{\mathcal{P}}$, and diagnostic model evaluated with averaged data $M$.

the contribution from the covariances between $u_{\dagger}^{\prime}, d_{z}^{\prime}$, and $\gamma_{s}^{\prime}$ as

$$
C_{u d \gamma}=\mathcal{I}\left(\bar{u}_{\dagger} \overline{d_{z}^{\prime} \gamma_{s}^{\prime}}+\bar{d}_{z} \overline{\gamma_{s}^{\prime} u_{\dagger}^{\prime}}+\bar{\gamma}_{s} \overline{u_{\dagger}^{\prime} d_{z}^{\prime}}+\overline{u_{\dagger}^{\prime} d_{z}^{\prime} \gamma_{s}^{\prime}}\right)
$$

Although the contribution of $C_{u d \gamma}$ to $\overline{\mathcal{P}}$ is not small, its influence on hydrological sensitivity can be neglected. To demonstrate this, let $\beta=1+C_{u d \gamma} / M$, in which case $\overline{\mathcal{P}}=\beta M$ and

$$
\frac{\delta \overline{\mathcal{P}}}{\overline{\mathcal{P}}}=\frac{\delta \beta}{\beta}+\frac{\delta M}{M} .
$$

Let $P_{\text {st }}$ be the stratiform precipitation rate from the simulations. The hydrological sensitivity $\delta \bar{P}_{\text {st }} / \bar{P}_{\text {st }}$ is compared to $\delta \overline{\mathcal{P}} / \overline{\mathcal{P}}$ and $\delta M / M$ as a function of latitude in Fig. 10. As will be the case throughout the following, the latitude range in Fig. 10 omits the $2^{\circ}$-wide bands adjacent to the north and south ends of the ridge where our diagnostic orographic precipitation model is less appropriate because a nontrivial fraction of the airstream is diverted laterally and does not pass over the barrier. Figure 10 shows that $\delta M / M$ provides a reasonably good approximation to both $\delta \bar{P}_{\mathrm{st}} / \bar{P}_{\mathrm{st}}$ and $\delta \overline{\mathcal{P}} / \overline{\mathcal{P}}$. Perhaps serendipitously, $\delta M / M$ actually gives a better approximation to exact hydrological sensitivity $\delta \bar{P}_{\text {st }} / \bar{P}_{\text {st }}$ than does $\delta \overline{\mathcal{P}} / \overline{\mathcal{P}}$ at latitudes north of $52^{\circ} \mathrm{N}$ 


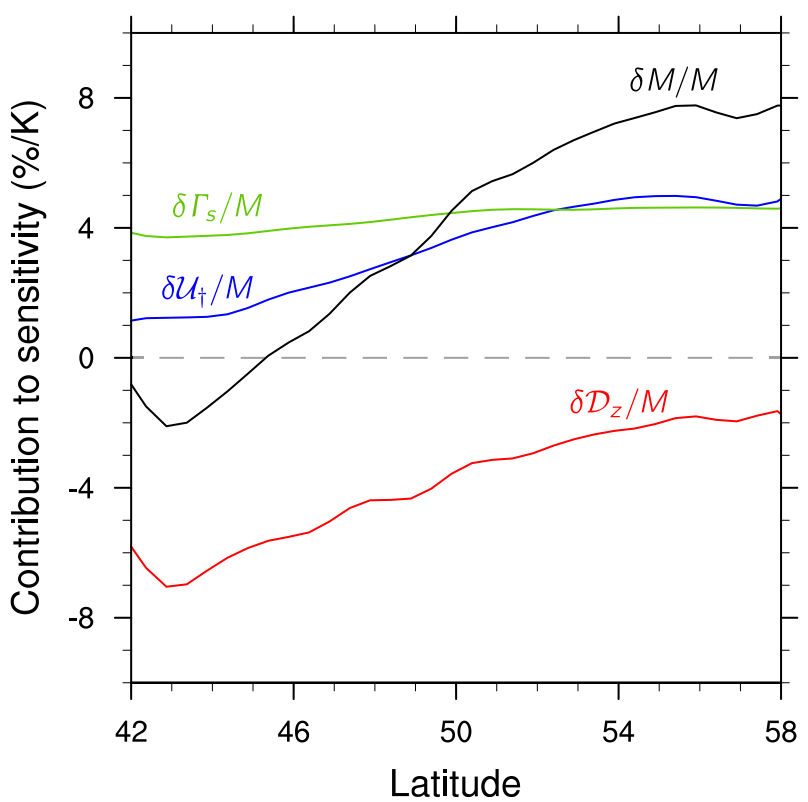

FIG. 11. Individual contributions to the change in mean stratiform orographic precipitation intensities from changes in westerly wind speed $\delta \mathcal{U}_{\dagger} / M$, the saturated vertical displacement $\delta \mathcal{D}_{z} / M$, and the lapse rate of saturation specific humidity $\delta \Gamma_{s} / M$, and their sum $\delta M / M$. All quantities are averaged over western sides of the mountains.

Since $\delta M / M$ depends only on simple annual averaged values while still providing a good approximation to $\delta \bar{P}_{\text {st }} / \bar{P}_{\text {st }}$ our focus in the following will be on those factors that determine $\delta M / M$. The contribution to $\delta M / M$ from warming-induced changes in the annual averaged lapse rate of saturation specific humidity $\delta \Gamma_{s}$, the annual averaged cross-mountain wind speed $\delta \mathcal{U}_{\dagger}$, and the annual averaged saturated vertical displacement $\delta \mathcal{D}_{z}$, satisfies

$$
\frac{\delta M}{M}=\frac{\delta \mathcal{I}\left(\bar{u}_{\dagger} \bar{d}_{z} \bar{\gamma}_{s}\right)}{M}=\frac{1}{M}\left(\delta \Gamma_{s}+\delta \mathcal{U}_{\dagger}+\delta \mathcal{D}_{z}\right)
$$

where

$$
\begin{aligned}
\delta \Gamma_{s} & =\mathcal{I}\left[\left(\delta \bar{\gamma}_{s}\right) \bar{u}_{\dagger} \bar{d}_{z}\right], \\
\delta \mathcal{U}_{\dagger} & =\mathcal{I}\left[\left(\delta \bar{u}_{\dagger}\right) \bar{d}_{z} \bar{\gamma}_{s}\right], \quad \text { and } \\
\delta \mathcal{D}_{z} & =\mathcal{I}\left[\left(\delta \bar{d}_{z}\right) \bar{\gamma}_{s} \bar{u}_{\dagger}\right]
\end{aligned}
$$

Figure 11 shows the contributions from each term in (12) to $\delta M / M$ (and therefore to good approximation, the contributions to the sensitivity of the annually averaged intensity of stratiform precipitation $\left.\delta \bar{P}_{\mathrm{st}} / \bar{P}_{\mathrm{st}}\right)$. The contribution from $\delta \Gamma_{s} / M$ is relatively uniform at all latitudes, while $\delta \mathcal{U}_{\dagger} / M$ and $\delta \mathcal{D}_{z} / M$ increase significantly from south to north. In the following subsections, we will discuss the processes responsible for the warming-induced changes

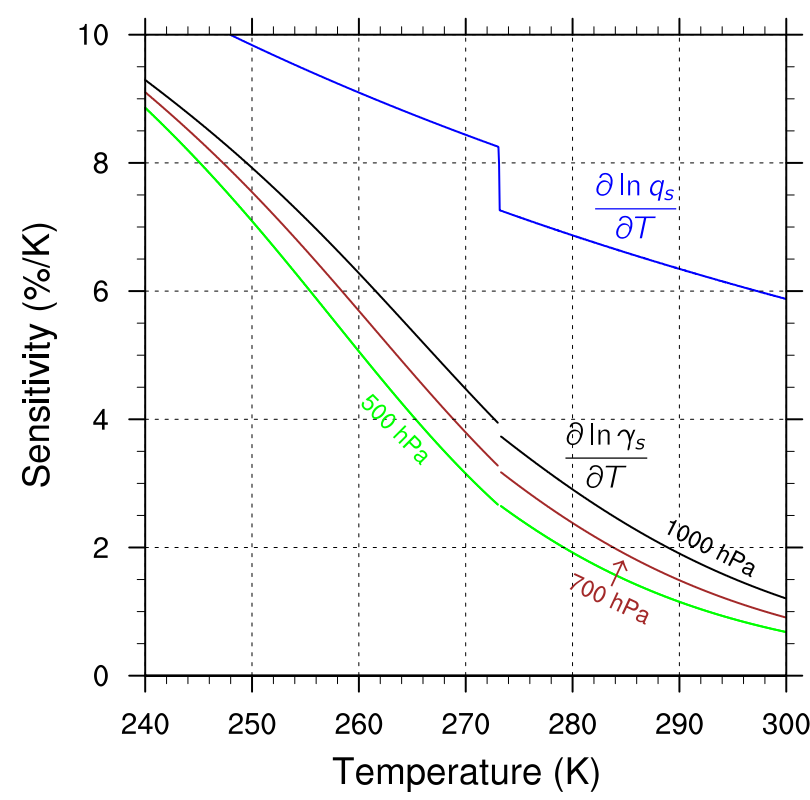

FIG. 12. The dependence of $\gamma_{s}$ and $q_{s}$ on temperature. The blue curve is $\delta \ln \left(q_{s}\right) / \partial T$, while other curves are values of $\delta \ln \left(\gamma_{s}\right) / \partial T$ at different pressure levels. The discontinuities are produced by our simple treatment of the transition between condensation and deposition.

$\delta \Gamma_{s}, \delta \mathcal{U}_{\dagger}$, and $\delta \mathcal{D}_{z}$, and their influence on the intensity of stratiform orographic precipitation.

\section{b. Lapse rate of saturation specific humidity}

According to Fig. $11, \delta \Gamma_{s} / M$ contributes about $4 \% \mathrm{~K}^{-1}$ toward the total hydrological sensitivity at all latitudes occupied by the mountains. From (6), $\gamma_{s}=q_{s} / H_{q_{s}}$, so if the scale height of saturation specific humidity were constant under climate change, $\delta \gamma_{s} / \gamma_{s}$ would match $\delta q_{s} /$ $q_{s}$ and increase at the $\mathrm{CC}$ rate of about $7 \% \mathrm{~K}^{-1}$ of surface warming. In fact $H_{q_{s}}$ is not constant; neglecting the step changes accompanying the transition between liquid and frozen hydrometeors, at constant pressure $H_{q_{s}}$ increases monotonically as a function of $T$. As a consequence, the increase in $\delta \gamma_{s} / \gamma_{s}$ with temperature is smaller than the increase in $\delta q_{s} / q_{s}$. Figure 12 shows that the difference between $\partial \ln \left(q_{s}\right) / \partial T$ and $\partial \ln \left(\gamma_{s}\right) / \partial T$ becomes substantial at warm temperatures, exceeding a factor of 2 for $T>\sim 270 \mathrm{~K}$. As is also evident from Fig. 12, $\partial \ln \left(\gamma_{s}\right) / \partial T$ is only weakly dependent on the pressure.

Because $\delta \gamma_{s} / \gamma_{s}<\delta q_{s} / q_{s}$, the fractional increase in the condensation generated by lifting saturated parcels a fixed vertical distance will increase more slowly as the climate warms than the fractional increase in the specific humidity itself (Betts and Harshvardhan 1987). The contribution of changes in $\gamma_{s}$ to the hydrological sensitivity of the diagnosed stratiform orographic precipitation is 


$$
\frac{\delta \Gamma_{s}}{M}=\frac{\mathcal{I}\left(\delta \bar{\gamma}_{s} \bar{u}_{\dagger} \bar{d}_{z}\right)}{\mathcal{I}\left(\bar{\gamma}_{s} \bar{u}_{\dagger} \bar{d}_{z}\right)} .
$$

The summation in both the numerator and the denominator is weighted by $\bar{u}_{\uparrow} \bar{d}_{z}$, which the simulations show to be dominated by contributions from the 850-600-hPa layer. The mean temperature in that layer is approximately $270 \mathrm{~K}$, which from Fig. 12 corresponds to a $700-\mathrm{hPa}$ value for $\partial \ln \left(\gamma_{s}\right) / \partial T$ of about $4 \% \mathrm{~K}^{-1}$, a value that is in good agreement with those plotted for $\delta \Gamma_{s} / M$ in Fig. 11.

\section{c. Westerly wind speed}

As evident in Fig. 11, the changes in cross-mountain wind speed $\delta \mathcal{U}_{\dagger}$ contribute $4 \%-5 \% \mathrm{~K}^{-1}$ to the total increase in orographic precipitation over the northern half of the range, a value very similar to the contribution from $\delta \Gamma_{s}$. But south of $44^{\circ} \mathrm{N}$, the contribution from $\delta \mathcal{U}_{\dagger}$ drops to just slightly more than $1 \% \mathrm{~K}^{-1}$. This northsouth asymmetry is produced by a poleward shift in the storm track, which is a common feature in global warming simulations. The physical mechanisms responsible for this shift are a topic of active investigation (e.g., Lorenz and DeWeaver 2007; Lu et al. 2010; Rivière 2011; Kidston et al. 2011).

To quantify the poleward shift of the storm track, we define the latitude of the eddy-driven jet following Ceppi and Hartmann (2013) as the latitude of the maximum zonal-mean zonal wind at the 850 -hPa pressure level. Using this definition, the Northern Hemisphere jet shifts poleward by $1.65^{\circ}$ as global mean surface temperature increases from M1 to M2. Interestingly, our Northern Hemisphere mountains produce an even larger $2.62^{\circ}$ poleward shift in the mountain-free Southern Hemisphere. In contrast, in both hemispheres of the aquaplanet the poleward shift of the jet between simulations A1 and A2 is $2.16^{\circ}$. The shifts in the jet are sensitive to the position of mountains. In simulations $\mathrm{M} 1^{\prime}$ and $\mathrm{M} 2^{\prime}$, in which the mountains lie between $35^{\circ}$ and $55^{\circ} \mathrm{N}$, the jets shift poleward $2.24^{\circ}$ and $2.53^{\circ}$ in the Northern and Southern Hemisphere, respectively.

\section{d. Saturated vertical displacement}

As apparent in Fig. 11, the change in saturated vertical displacement $\delta \mathcal{D}_{z}$ has a large negative impact on the overall hydrological sensitivity. Consistent with (8), $d_{z}$ may be expressed in terms of the Heaviside function $H$ as

$$
d_{z}=\left(z^{* *}-z^{*}\right) H\left(z^{* *}-z^{*}\right),
$$

showing that $d_{z}$ is not a linear function of $z^{* *}$ and $z^{*}$ and therefore $\bar{d}_{z} \neq \overline{z^{* *}}-\overline{z^{*}}$. Whereas $\delta \Gamma_{s}$ and $\delta \mathcal{U}_{\dagger}$ depend solely on the time averages of elementary fields, such as the westerly wind speed, $\delta \mathcal{D}_{z}$ is the time average of episodic vertical motions lifting air parcels to saturation.

The preceding is verified in Figs. 13a-c, which show meridional cross sections along the topography above the second-from-the-west grid cell (i.e., $1.56^{\circ}$ west of the ridgeline); $\delta \bar{d}_{z}$ is clearly not the sum of $\delta \bar{z}^{* *}$ and $-\delta \bar{z}$. Figure $13 \mathrm{c}$ shows the vertical displacement required to reach the LCL during nonnegligible precipitation events is $40-100 \mathrm{~m}$ larger in M2 than in M1 at most heights greater than about $2 \mathrm{~km}$. Particularly in the south, $-\delta \overline{z^{*}}$ dominates the other two terms; $\delta \bar{d}_{z}$ can remain significantly smaller than $-\delta \overline{z^{*}}$ because fewer vertical levels in a given column become saturated during precipitation events at the climate warms. Detailed analysis of this change in the frequency of saturation is given in appendix $\mathrm{B}$.

The change in LCL is primarily as a result of changes in relative humidity, as is evident from a comparison of Figs. $13 \mathrm{c}$ and $13 \mathrm{~d}$; there is drying between the heights of 1.5 and $4 \mathrm{~km}$ superimposed on a substantial meridional gradient with dryness increasing to the south at all heights above the southern half of the mountain. The north-south gradient in $\delta \mathrm{RH}$ is associated with the north-south shifts in the storm track. ${ }^{5}$ The large northsouth gradient in the sensitivity of the saturated vertical displacement $\left(\delta \mathcal{D}_{z} / M\right)$ apparent in Fig. 11 is therefore primarily due to changes in relative humidity associated with the poleward shift of storm tracks.

\section{Conclusions}

It is difficult to untangle all the factors regulating the changes in precipitation forced by Earth's topography in realistic GCM simulations of warmer climates. As a first step, we compared the relative influence of thermodynamics and dynamics on the hydrological sensitivity of midlatitude orographic precipitation over the western slopes of four major north-south barriers equally spaced around the Northern Hemisphere of a planet otherwise covered by ocean. Our mountains are smooth and wide enough to be reasonably represented on the numerical mesh, allowing the dynamics of stratiform precipitation to be simulated with minimal parameterization. Interestingly, the latitudinal (along the ridgeline) hydrological sensitivity in the GCM simulations turns out to be similar for both stratiform and convective precipitation. Nevertheless, because of uncertainties in the accuracy of convective parameterizations (particularly

\footnotetext{
${ }^{5}$ The reason for the vertical gradients in $\delta \mathrm{RH}$ is a subject of continued study.
} 

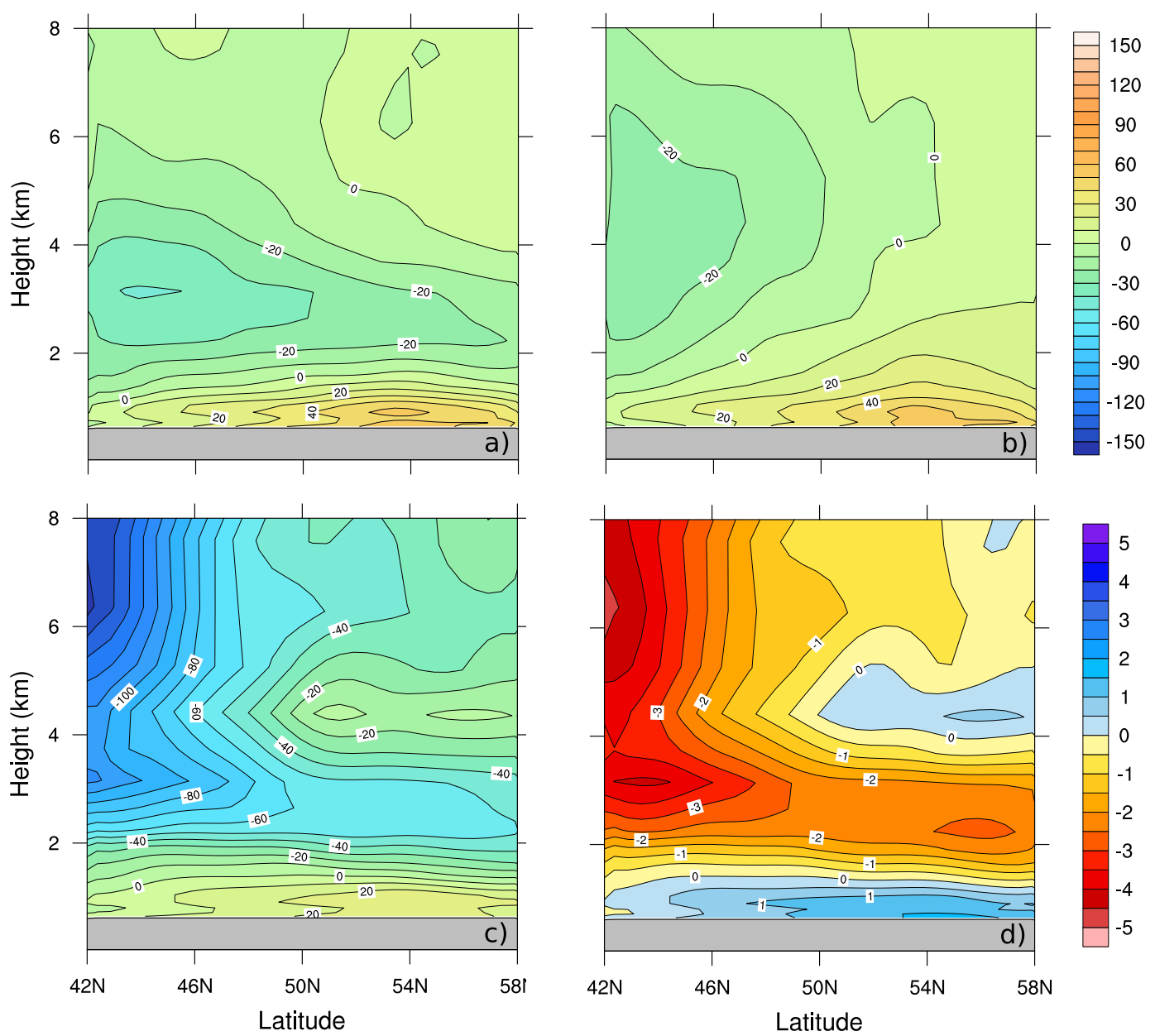

FIG. 13. Meridional cross sections above the second cell east of the base of the mountain showing the mean rainytime difference M2 - M1 of (a) $\delta \overline{d_{z}}$, (b) $\delta \overline{z^{* *}}$, and (c) $-\delta \overline{z^{*}}$, contoured at 10-m intervals. (d) Contours of $\delta \overline{(\mathrm{RH})}$ at intervals of $0.5 \%$.

over mountains), our detailed analysis focuses on the stratiform precipitation.

In our simulations, the changes in midlatitude orographic precipitation due to global warming show a strong north-south asymmetry. The water vapor fluxes impinging on the ridges strengthen at all latitudes even as precipitation decreases near the southern ends of the mountains and increases in the north. For mountains stretching from $40^{\circ}$ to $60^{\circ} \mathrm{N}$, the hydrological sensitivity exceeds the $\mathrm{CC}$ scaling over the entire northern half of the range. A maximum in the hydrological sensitivity of $14 \% \mathrm{~K}^{-1}$ occurs near the northern end of the range, which given the $2.56-\mathrm{K}$ increase in global-mean surface temperature obtained when $\mathrm{CO}_{2}$ is increased from 330 to $660 \mathrm{ppm}$, corresponds to a substantial $36 \%$ increase in the north. Conversely, near the southern end of the range, precipitation decreases as a slight shift in a region of steep precipitation gradients produces a sensitivity of
$-6 \% \mathrm{~K}^{-1}$. In contrast to the total annual precipitation, the frequency of extreme events does increase at all latitudes. The greatest increase in these extremes, exceeding a factor of 2 , is in the north.

The changes in accumulated precipitation are due to differences in both intensity and frequency. Except in the extreme south, the change in precipitation intensity makes the larger contribution. Nevertheless, the changes in the number of hours with precipitation are also quite significant. In the north, for example, more frequent precipitation contributes $5 \% \mathrm{~K}^{-1}$ toward a total sensitivity of $14 \% \mathrm{~K}^{-1}$. The latitudinal dependence of the sensitivity to surface warming in the annual average number of hours during which precipitation occurs closely tracks that of the 2-8-day bandpass-filtered vertical velocity variance, suggesting that changes in the frequency of precipitation are primarily driven by changes in the frequency of midlatitude storms. Such 
changes in storminess are not captured in pseudoglobal warming experiments (Hara et al. 2008; Rasmussen et al. 2011 ), in which the climatological means are shifted to match those in warmer-world GCM simulations, but the day-to-day weather is driven by perturbations at the lateral boundaries whose frequencies and intensities match those in the current climate.

The stratiform precipitation intensity in the full AM2.1 depends on many variables via a complex parameterization. The changes in the average stratiform precipitation intensity can, however, be well approximated using a simple diagnostic model involving three factors: the moist adiabatic lapse rate of saturation specific humidity $\delta \Gamma_{s}$, the westerly wind speed $\delta \mathcal{U}_{\dagger}$, and the saturated vertical displacement $\delta \mathcal{D}_{z}$. The contribution of $\delta \Gamma_{s}$ to changes in orographic precipitation intensity is primarily governed by the Clausius-Clapeyron equation and is a relatively uniform $4 \%-5 \% \mathrm{~K}^{-1}$ at all latitudes. Modifications in the westerly wind speed $\delta \mathcal{U}_{\dagger}$ also make a positive contribution to the change in annual average orographic precipitation, ranging from $1 \% \mathrm{~K}^{-1}$ in the south to $5 \% \mathrm{~K}^{-1}$ in the north because of the northward shift of the storm track. Changes in the saturated vertical displacement $\mathcal{D}_{z}$ produce a north-south gradient similar to those associated with $\delta \mathcal{U}_{+}$, but are negative at all latitudes, ranging from $-7 \% \mathrm{~K}^{-1}$ in the south to $-2 \% \mathrm{~K}^{-1}$ in the north. The north-south variation in $\delta \mathcal{D}_{z}$ is primarily driven by changes in the relative humidity aloft during rainy events, which in turn appears to be associated with northward shifts in the storm tracks.

In summary, stratiform midlatitude orographic precipitation responds in different ways to the changes in thermodynamics and dynamics simulated by the GCM in response to doubled $\mathrm{CO}_{2}$. Thermodynamic changes (warmer temperatures and higher specific humidities) are responsible for an almost uniform positive hydrological sensitivity of $4 \%-5 \% \mathrm{~K}^{-1}$ on the windward slopes of the mountains. Yet the actual hydrological sensitivity is far different and is largely driven by dynamical changes resulting from shifts in the storm tracks and storm frequency. The strong north-south gradients in the actual hydrological sensitivity (see Fig. 5) suggest that attempts to simulate finescale global warminginduced changes in orographic precipitation with regional climate models will be highly dependent on the accuracy of the large-scale flows used to force the regional circulations.

Many additional physical processes and much higher numerical resolution would need to be included in the model before attempting to make predictions for specific real-world locations. Convection is a key physical process that is crudely parameterized in the GCM and not included in our diagnostic model. Cannon et al.
(2012) suggest that changes in embedded convection owing to warmer less stable upstream flows might significantly modify orographic precipitation over narrow mountain ridges, but would generate only a modest $6 \%-$ $12 \%$ increase over wide ridges such as those considered in this study. There are also a wide variety of possible terrain configurations that might be explored through similar numerical experiments. We briefly considered identical ridges located $5^{\circ}$ farther south $\left(35^{\circ}-55^{\circ} \mathrm{N}\right)$ and found latitudinal gradients in the hydrological sensitivity similar to those in the $40^{\circ}-60^{\circ} \mathrm{N}$ case.

Acknowledgments. The authors have benefited from conversations with Dargan Frierson, David Battisti, and the comments of two anonymous reviewers. This research was supported by National Science Foundation (NSF) Grant AGS-1138977 and used computing resources provided by the University of Washington eScience Institute and the Extreme Science and Engineering Discovery Environment (XSEDE), which is supported by NSF Grant OCI-1053575.

\section{APPENDIX A}

\section{The Moist Lapse Rate of Saturation Specific Humidity and the Lifting Condensation Level}

The moist pseudoadiabatic lapse rate of saturation specific humidity can be expressed as

$$
\gamma_{s}=-\frac{d q_{s}}{d z}=-\frac{d q_{s}}{d T} \frac{d T}{d z}=\frac{d q_{s}}{d T} \Gamma_{m}
$$

where $\Gamma_{m}=-d T / d z$ is the moist pseudoadiabatic lapse rate. Let $e_{s}$ represent the saturation vapor pressure, $p$ the environmental pressure, and $\epsilon$ the ratio of the gas constant for dry air $R_{d}$ to that for water vapor $R_{v}$. Then

$$
q_{s}=\frac{\epsilon e_{s}}{p-e_{s}(1-\epsilon)} \approx \frac{\epsilon e_{s}}{p}
$$

and

$$
\gamma_{s}=\epsilon\left(\frac{1}{p} \frac{d e_{s}}{d T}-\frac{e_{s}}{p^{2}} \frac{d p}{d T}\right) \Gamma_{m}
$$

In the preceding equation, replace $d e_{s} / d T$ using the Clausius-Clapeyron equation,

$$
\frac{d e_{s}}{d T}=\frac{L e_{s}}{R_{v} T^{2}},
$$

and $d p / d T$ using the hydrostatic equation,

$$
\frac{d p}{d T}=\frac{d p}{d z} \frac{d z}{d T}=\frac{p g}{R_{d} T \Gamma_{m}},
$$


to obtain

$\gamma_{s}=\epsilon\left(\frac{e_{s}}{p} \frac{L}{R_{v} T^{2}}-\frac{e_{s}}{p} \frac{g}{R_{d} T \Gamma_{m}}\right) \Gamma_{m}=q_{s}\left(\frac{L \Gamma_{m}}{R_{v} T^{2}}-\frac{g}{R_{d} T}\right)$,

which is (6).

The expression for $\Gamma_{m}$ can be found in Emanuel (1994, p. 131). After neglecting the heat capacity of liquid water/ice, it is

$$
\Gamma_{m}=\frac{g}{c_{p d}} \frac{1+r_{s}}{1+r_{s} \frac{c_{p v}}{c_{p d}}}\left[\frac{1+\frac{L r_{s}}{R_{d} T}}{1+\frac{L^{2} r_{s}\left(1+r_{s} / \epsilon\right)}{R_{v} T^{2}\left(c_{p d}+r_{s} c_{p v}\right)}}\right],
$$

where $r_{s}$ is the mixing ratio of water vapor, and $L$ is the latent heat of vaporization (for $T \geq 273.15 \mathrm{~K}$ ) or sublimation (for $T<273.15 \mathrm{~K})\left(c_{p d}\right.$ and $c_{p v}$ are heat capacity at constant pressure for dry air and water vapor, respectively).

The saturation vapor pressure over water can be appreciably different from that over ice at low temperatures, so our diagnostic model must differentiate between condensation and deposition. In reality, condensation, deposition, and freezing may take place at the same time in mixed-phase clouds. But in keeping with the simplicity of our diagnostic model, condensation is assumed to occur when the temperature of an air parcel is above $0^{\circ} \mathrm{C}$, and deposition is assumed for temperatures below $0^{\circ} \mathrm{C}$. The lifting condensation level was computed following Bolton (1980) and Emanuel (1994, chapter 4) as

$z^{*}= \begin{cases}\frac{1}{\Gamma_{d}}\left[T-55.0-\left(\frac{1}{T-55.0}-\frac{\ln \phi_{w}}{2840}\right)^{-1}\right], & T \geq T_{0}, \\ \frac{1}{\Gamma_{d}}\left[T-18.7-\left(\frac{1}{T-18.7}-\frac{\ln \phi_{i}}{4504}\right)^{-1}\right], & T<T_{0},\end{cases}$

where $T_{0}=273.15 \mathrm{~K}$ and $\Gamma_{d}$ is dry adiabatic lapse rate, while $\phi_{w}$ and $\phi_{i}$ are the relative humidities with respect to water and ice, respectively.

\section{APPENDIX B}

\section{Changes in the Frequency of Lifting Parcels to their LCL}

It is difficult to isolate the precise factors responsible for the changes in $\delta \mathcal{D}_{z}$, so we define a closely related quantity more amenable to further analysis. Let $j$ be the time index for archived simulation data. For each grid cell, let $J$ be the set of all $j$ for which the precipitation intensity, averaged over the four cells in the east-west line up the western slope that includes the cell, is at least $0.02 \mathrm{~mm} \mathrm{~h}^{-1}$. Define $\tilde{J}$ to be the subset of $j \in J$ for which parcels in that cell are lifted to their lifting condensation level (LCL; i.e., for which $z_{j}^{* *}-z_{j}^{*}>0$ ). Suppose there are $N$ elements in set $J$ and $n$ elements in $\tilde{J}$. Then

$$
\bar{d}_{z}=\frac{1}{N} \sum_{j \in \tilde{J}}\left(z_{j}^{* *}-z_{j}^{*}\right) .
$$

Also define

$$
\widetilde{z^{* *}}=\frac{1}{n} \sum_{j \in \tilde{J}} z_{j}^{* *} \quad \text { and } \quad \widetilde{z^{*}}=\frac{1}{n} \sum_{j \in \tilde{J}} z_{j}^{*}
$$

which represent the average values of $z^{* *}$ and $z^{*}$ over just those instances when the precipitation is nonnegligible and parcels are also lifted to their LCL. From (B1) and (B2),

$$
\left.\bar{d}_{z}=\widetilde{\left(z^{* *}\right.}-\widetilde{z^{*}}\right) \frac{n}{N}
$$

and the fractional change $\delta \bar{d}_{z} / \bar{d}_{z}$ satisfies

$$
\delta \ln \left(\bar{d}_{z}\right)=\delta \ln \left(\widetilde{z^{* *}}-\widetilde{z^{*}}\right)+\delta \ln (n / N) .
$$

Define the weighted vertical average operator $\langle\cdot\rangle_{z}$ such that

$$
\langle\cdot\rangle_{z}=\frac{\mathcal{I}\left[(\cdot) \bar{u}_{\dagger} \bar{\gamma}_{s}\right]}{\mathcal{I}\left[\bar{u}_{\dagger} \bar{\gamma}_{s}\right]}
$$

Figure $\mathrm{B} 1$ shows the latitudinal variations in $\delta \mathrm{D}_{z} / M$ and this weighted average of each term in (B3). As in Fig. 11, the value plotted for each latitude is averaged over the four cells along an east-west line up the western sides of the four mountains. While $\left\langle\delta \ln \left(\bar{d}_{z}\right)\right\rangle_{z}$ is not exactly identical to $\delta \mathcal{D}_{z} / M$, its sensitivity to changes in surface temperature is very similar to that of $\delta \mathcal{D}_{z} / M$. In particular, both $\delta \mathcal{D}_{z} / M$ and $\left\langle\delta \ln \left(\bar{d}_{z}\right)\right\rangle_{z}$ increase almost monotonically from large negative values in the south to small negative values in the north. Figure B1 also shows that both terms in (B1) contribute to the negative values of $\left\langle\delta \ln \left(\bar{d}_{z}\right)\right\rangle_{z}$, but the latitudinal gradient in $\left\langle\delta \ln \left(\bar{d}_{z}\right)\right\rangle_{z}$ arises primarily from the latitudinal gradient in $\langle\delta \ln (n / N)\rangle_{z}$. Moreover, $\langle\delta \ln (n / N)\rangle_{z}$ provides the largest contribution to $\left\langle\delta \ln \left(\bar{d}_{z}\right)\right\rangle_{z}$ in the southern half of the mountain range. 


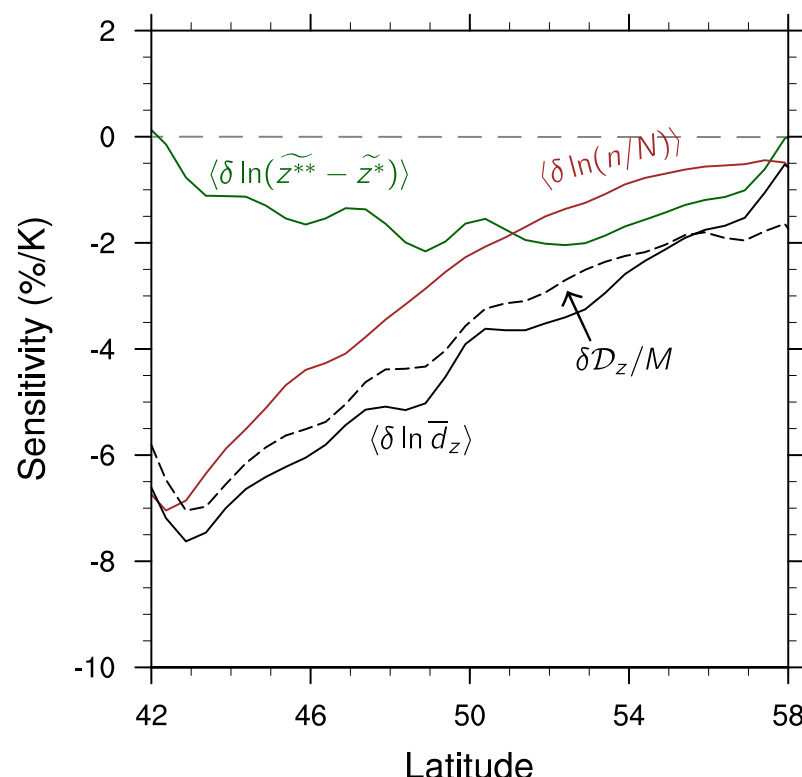

FIG. B1. Latitudinal variations in the sensitivities with respect to surface temperature in the saturated vertical displacement $\delta D_{z} / M$, its approximation $\left\langle\delta \ln \left(\bar{d}_{z}\right)\right\rangle_{z}$, and the two components that sum to form the approximation, $\langle\delta \ln (n / N)\rangle_{z}$ and $\left\langle\delta \ln \left(\widetilde{z^{* *}}-\widetilde{z^{*}}\right)\right\rangle_{z}$. All quantities are averaged over western sides of the mountains.

\section{REFERENCES}

Allen, M., and W. Ingram, 2002: Constraints on future changes in climate and the hydrologic cycle. Nature, 419, 224-232, doi:10.1038/nature01092.

Alpert, P., 1986: Mesoscale indexing of the distribution of orographic precipitation over high mountains. J. Climate Appl. Meteor., 25, 532-545, doi:10.1175/1520-0450(1986)025<0532: MIOTDO $>2.0 . \mathrm{CO} ; 2$.

Anderson, J. L., and Coauthors, 2004: The new GFDL global atmosphere and land model AM2-LM2: Evaluation with prescribed SST simulations. J. Climate, 17, 4641-4673, doi:10.1175/ JCLI-3223.1.

Beniston, M., 2005: Mountain climates and climatic change: An overview of processes focusing on the European Alps. Pure Appl. Geophys., 162, 1587-1606, doi:10.1007/ s00024-005-2684-9.

Betts, A. K. and Harshvardhan, 1987: Thermodynamic constraint on the cloud liquid water feedback in climate models. J. Geophys. Res., 92 (D7), 8483-8485, doi:10.1029/JD092iD07p08483.

Bolton, D., 1980: The computation of equivalent potential temperature. Mon. Wea. Rev., 108, 1046-1053, doi:10.1175/ 1520-0493(1980)108<1046:TCOEPT>2.0.CO;2.

Cannon, D. J., D. J. Kirshbaum, and S. L. Gray, 2012: Under what conditions does embedded convection enhance orographic precipitation? Quart. J. Roy. Meteor. Soc., 138, 391-406, doi:10.1002/qj.926.

Ceppi, P., and D. L. Hartmann, 2013: On the speed of the eddy-driven jet and the width of the Hadley cell in the Southern Hemisphere. J. Climate, 26, 3450-3465, doi:10.1175/JCLI-D-12-00414.1.

Emanuel, K. A., 1994: Atmospheric Convection. Oxford University Press, $580 \mathrm{pp}$.
Hara, M., T. Yoshikane, H. Kawase, and F. Kimura, 2008: Estimation of the impact of global warming on snow depth in Japan by the pseudo-global-warming method. Hydrol. Res. Lett., 2, 61-64, doi:10.3178/hrl.2.61.

Held, I. M., and B. Soden, 2006: Robust responses of the hydrological cycle to global warming. J. Climate, 19, 5686-5699, doi:10.1175/JCLI3990.1.

Kidston, J., G. K. Vallis, S. M. Dean, and J. A. Renwick, 2011: Can the increase in the eddy length scale under global warming cause the poleward shift of the jet streams? J. Climate, 24, 3764-3780, doi:10.1175/2010JCLI3738.1.

Kirshbaum, D. J., and R. B. Smith, 2008: Temperature and moiststability effects on midlatitude orographic precipitation. Quart. J. Roy. Meteor. Soc., 134, 1183-1199, doi:10.1002/qj.274.

Liepert, B., and M. Previdi, 2009: Do models and observations disagree on the rainfall response to global warming? J. Climate, 22, 3156-3166, doi:10.1175/2008JCLI2472.1.

Lin, S.-J., 2004: A “vertically Lagrangian” finite-volume dynamical core for global models. Mon. Wea. Rev., 132, 2293-2307, doi:10.1175/1520-0493(2004)132<2293:AVLFDC>2.0.CO;2.

Lin, Y.-L., S. Chiao, T.-A. Wang, M. L. Kaplan, and R. P. Weglarz, 2001: Some common ingredients for heavy orographic rainfall. Wea. Forecasting, 16, 633-660, doi:10.1175/ 1520-0434(2001)016<0633:SCIFHO > 2.0.CO;2.

Lorenz, D. J., and E. T. DeWeaver, 2007: Tropopause height and zonal wind response to global warming in the IPCC scenario integrations. J. Geophys. Res., 112, D10119, doi:10.1029/ 2006JD008087.

Lu, J., G. Chen, and D. M. W. Frierson, 2010: The position of the midlatitude storm track and eddy-driven westerlies in aquaplanet AGCMs. J. Atmos. Sci., 67, 3984-4000, doi:10.1175/ 2010JAS3477.1.

Maddox, R., L. Hoxit, C. Chappell, and F. Caracena, 1978: Comparison of meteorological aspects of the big Thompson and Rapid City flash floods. Mon. Wea. Rev., 106, 375-389, doi:10.1175/1520-0493(1978)106<0375:COMAOT>2.0.CO;2.

Minder, J. R., D. R. Durran, G. H. Roe, and A. M. Anders, 2008: The climatology of small-scale orographic precipitation over the Olympic Mountains: Patterns and processes. Quart. J. Roy. Meteor. Soc., 134, 817-839, doi:10.1002/qj.258.

Moorthi, S., and M. J. Suarez, 1992: Relaxed Arakawa-Schubert: A parameterization of moist convection for general circulation models. Mon. Wea. Rev., 120, 978-1002, doi:10.1175/ 1520-0493(1992)120<0978:RASAPO > 2.0.CO;2.

O'Gorman, P. A., and T. Schneider, 2009: The physical basis for increases in precipitation extremes in simulations of 21stcentury climate change. Proc. Natl. Acad. Sci. USA, 106, 14773-14777, doi:10.1073/pnas.0907610106.

- R. Allan, M. Byrne, and M. Previdi, 2012: Energetic constraints on precipitation under climate change. Surv. Geophys., 33, 585-608, doi:10.1007/s10712-011-9159-6.

Rasmussen, K. L., and R. A. Houze, 2012: A flash-flooding storm at the steep edge of high terrain. Bull. Amer. Meteor. Soc., 93, 1713-1724, doi:10.1175/BAMS-D-11-00236.1.

Rasmussen, R., and Coauthors, 2011: High-resolution coupled climate runoff simulations of seasonal snowfall over Colorado: A process study of current and warmer climate. J. Climate, 24, 3015-3048, doi:10.1175/2010JCLI3985.1.

Rivière, G., 2011: A dynamical interpretation of the poleward shift of the jet streams in global warming scenarios. J. Atmos. Sci., 68, 1253-1272, doi:10.1175/2011JAS3641.1.

Rotstayn, L. D., 1997: A physically based scheme for the treatment of stratiform clouds and precipitation in large-scale models. I: 
Description and evaluation of the microphysical processes. Quart. J. Roy. Meteor. Soc., 123, 1227-1282, doi:10.1002/ qj. 49712354106.

_, B. F. Ryan, and J. J. Katzfey, 2000: A scheme for calculation of the liquid fraction in mixed-phase stratiform clouds in largescale models. Mon. Wea. Rev., 128, 1070-1088, doi:10.1175/ 1520-0493(2000)128<1070:ASFCOT>2.0.CO;2.

Scheff, J., and D. Frierson, 2012: Twenty-first-century multimodel subtropical precipitation declines are mostly midlatitude shifts. J. Climate, 25, 4330-4347, doi:10.1175/JCLI-D-11-00393.1.

Smith, R. B., 1979: The influence of the mountains on the atmosphere. Advances in Geophysics, Vol. 21, Academic Press, 87-230.

—, Q. Jiang, M. G. Fearon, P. Tabary, M. Dorninger, J. D. Doyle, and R. Benoit, 2003: Orographic precipitation and air mass transformation: An Alpine example. Quart. J. Roy. Meteor. Soc., 129, 433-454, doi:10.1256/qj.01.212.

Takahashi, K., 2009: Radiative constraints on the hydrological cycle in an idealized radiative-convective equilibrium model. J. Atmos. Sci., 66, 77-91, doi:10.1175/2008JAS2797.1.

Ulbrich, U., J. Pinto, H. Kupfer, G. Leckebusch, T. Spangehl, and M. Reyers, 2008: Changing Northern Hemisphere storm tracks in an ensemble of IPCC climate change simulations. J. Climate, 21, 1669-1679, doi:10.1175/2007JCLI1992.1.

Yin, J. H., 2005: A consistent poleward shift of the storm tracks in simulations of 21 st century climate. Geophys. Res. Lett., 32, L18701, doi:10.1029/2005GL023684.

Zängl, G., 2008: The temperature dependence of small-scale orographic precipitation enhancement. Quart. J. Roy. Meteor. Soc., 134, 1167-1181, doi:10.1002/qj.267. 